
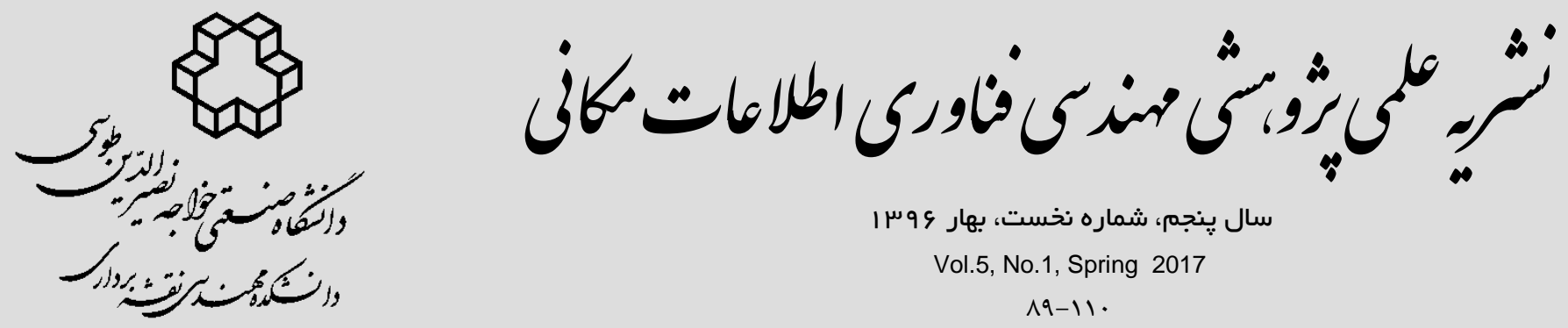

سال ينجم، شماره نخست، بهار و وس ا

Vol.5, No.1, Spring 2017

19-11.

ارزيابى توانايى الكوريتهم سوير ييكسل SLIC به تهمر اه الكوريتم خوشهبندى DBSCAN در قطعهبندى تصاوير سنجشازدورى با توان تفكيك مكانى بالا از مناطق شهرى

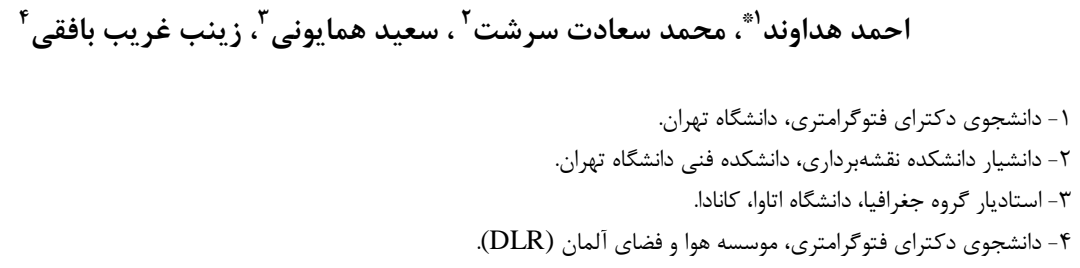

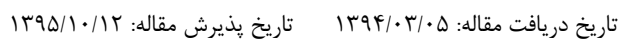

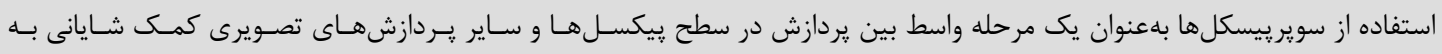

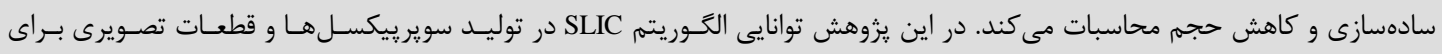

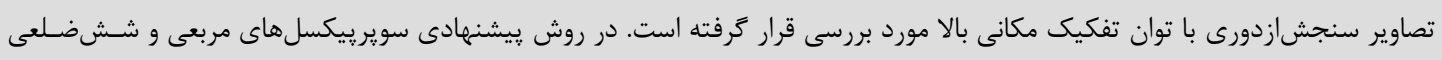

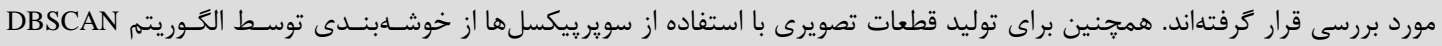

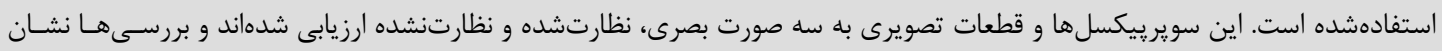

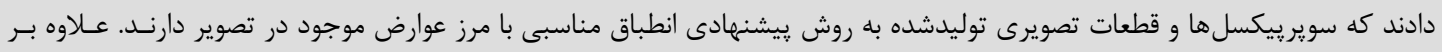

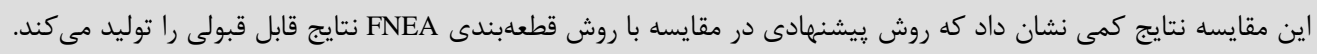

كليدوازهها: سوير ييكسل، قطعهبندى، سنجشازدور، توان تفكيك مكانى بالا، تصوير. 


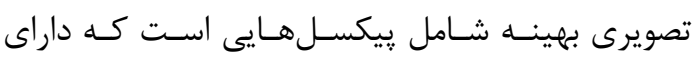

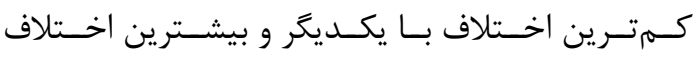
با پيكسل هاى موجود در قطعات مجاور هستند.

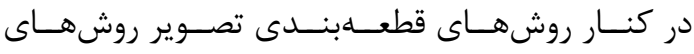

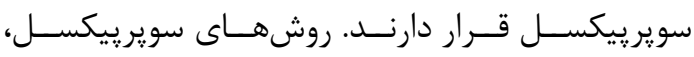

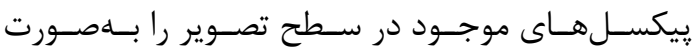

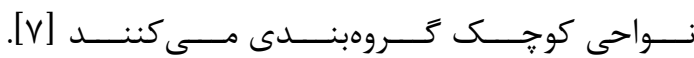

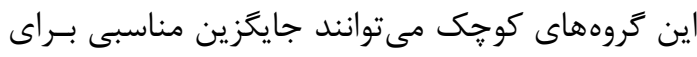

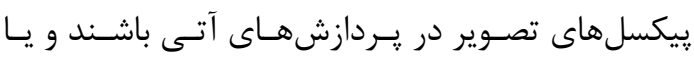
بهعنوان يك ورودى واسط براى توليد قطعات تصـويرى

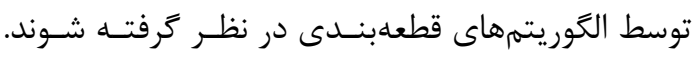

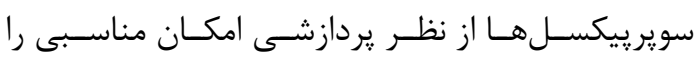

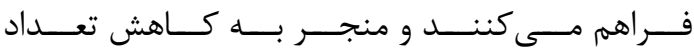
واحدهاى يردازشى مىشوند. الكوريتمهاى قطعهبندى تصوير به وفـور در كاربردهـاى مربوط به سنجشازدور مورد استفاده قرار ترفتهاند [N].

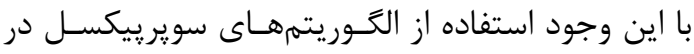

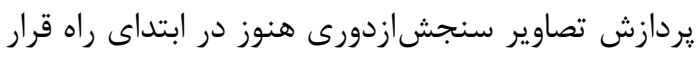

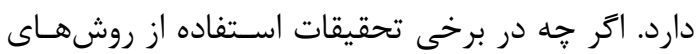

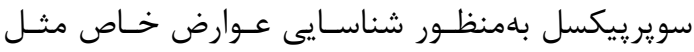

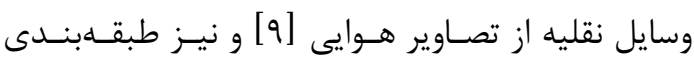

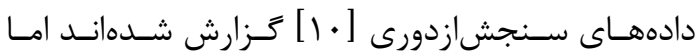

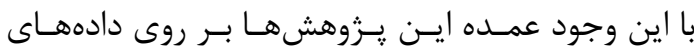

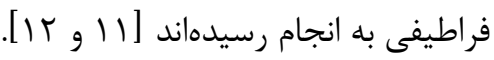
با توجه به عملكرد مناسب الكوريتمهاى سويرييكسل و و

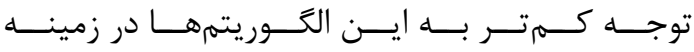

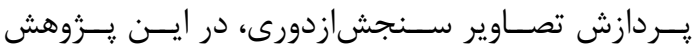

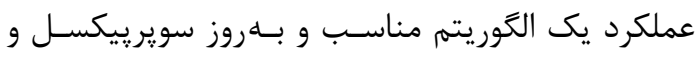

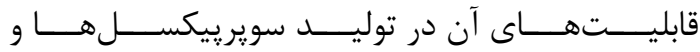
قطعات تصويرى از تصاوير سنجشازدور با توان تفكيـك

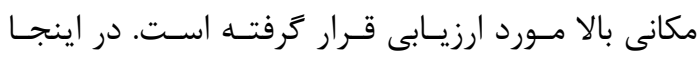

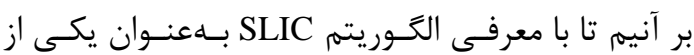

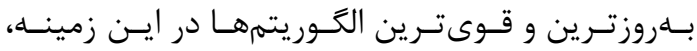

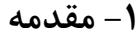

"يس از توسـعه و يرتـاب سـنجندههـاى تصـويربردارى ماهوارهاى مشاهدهى زمين با توان تفكيك مكـانى بـالا،

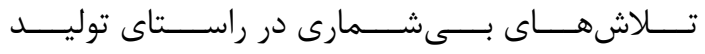
نقشههاى بوششى با كيفيت به انجام رسيده اسـت [1]

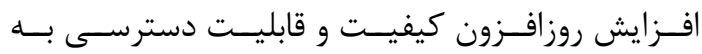
تصاوير هوايى و ماهوارهاى با تـوان تفكيـك مكـانى بـالا

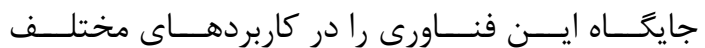

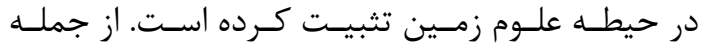

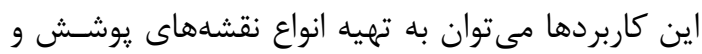

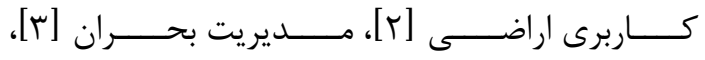

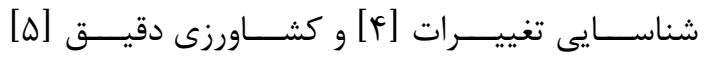

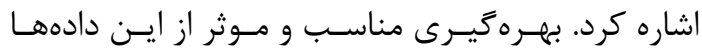

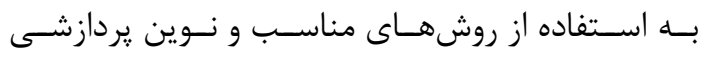

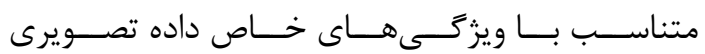
مورد استفاده بستخى دارد. با توجه به ماهيت تصـويرى

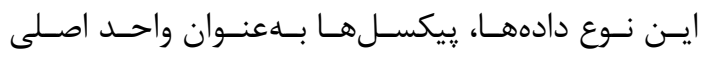

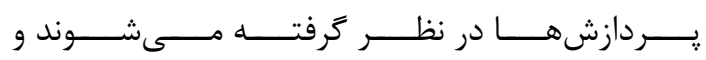

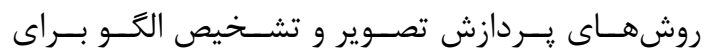

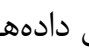

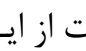

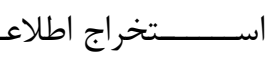
مورد استفاده قرار مى קيكسلهاى تشكيلدهنده تصاوير، ورودى مناسبى براى

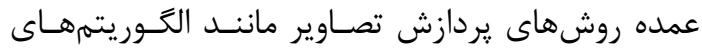

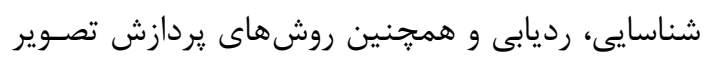

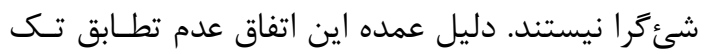

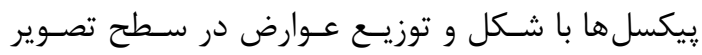

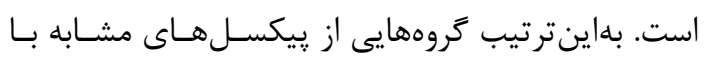

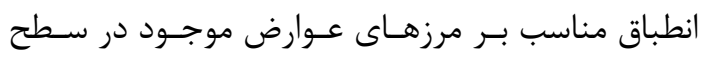
تصوير مىتوانند بهعنوان ورودى هاى سطح بـالاتر بـراى اين الكوريتمها به كار گرفته شوند.

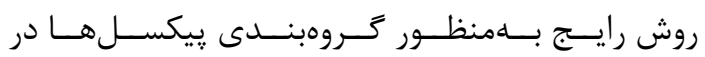
يردازش تصاوير تحت عنوان روش قطعـهبنـدى تصـوير

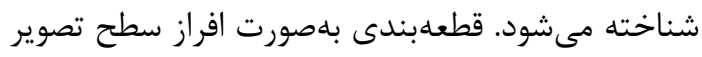

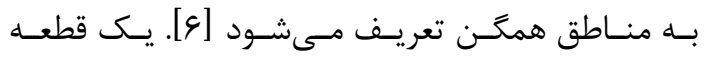


اين الكوريتم توسط گر اديانهاى محلى محاسبه مى شود

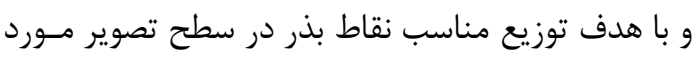

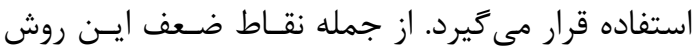
مىتوان به حجم بالاى محاسبات در آن اشاره كرد. در ميان الكوريتهماى سوير يُيسكل موجود، در الكوريته SLIC

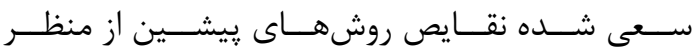
حجم محاسبات و يردازشهــا و نيـز انطبـاق بــا لبـهـهـا

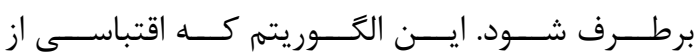

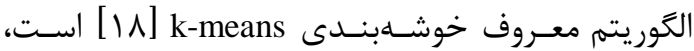
با ايجاد محدوديت در محاسبه فاصله در محدودهاى كـهـ

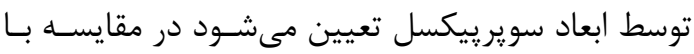

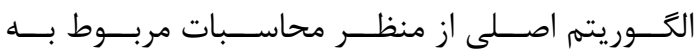

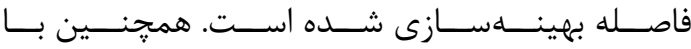

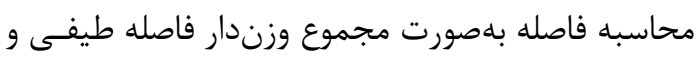

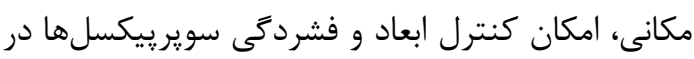

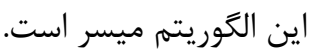

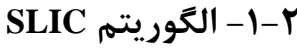
تنها يارامتر ورودى اين الكَوريتم كه با الهام از الحَــوريتهم

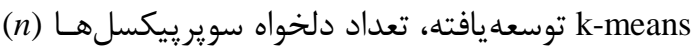

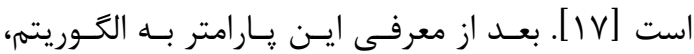

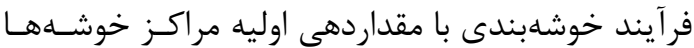
ب س بـ

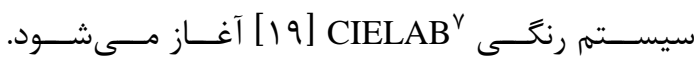

\footnotetext{
${ }^{6}$ Simple linear iterative clustering

${ }^{7}$ A Lab color space is a color-opponent space with dimension $\mathrm{L}$ for lightness and $\mathrm{a}$ and $\mathrm{b}$ for the coloropponent dimensions, based on nonlinearly compressed (e.g. CIE XYZ ) coordinates. The terminology originates from the three dimensions of the Hunter 1948 color space, which are L, a, and b. However, Lab is now more often used as an informal abbreviation for the L-a-b representation of the CIE 1976 color space (or CIELAB). The difference between the original Hunter and CIE color coordinates is that the CIE coordinates are based on a cube root transformation of the color data, while the Hunter coordinates are based on a square root transformation. Other examples of color spaces with Lab
}

عملكرد اين روش را در مقايسه بـا الخـوريتمههـاى رايـج قطعهبندى مورد ارزيابى قرار دهيم.

\section{ץ- الكَوريتهمهاى سوير ييكسل}

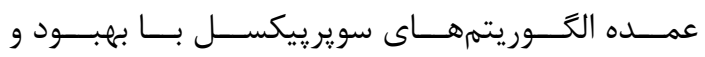

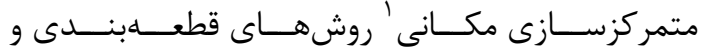
خوشهبندى توسعهيافتهانـد. از جملـه ايسن الخـوريتهمهـا

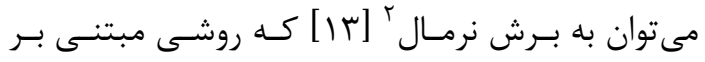

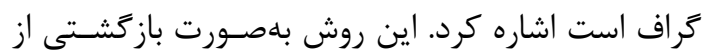
بخشبندى يك گراف متشـكل از ييكسـلـهـاى تصـوير با توجه به اطلاعات لبه و بافت تصوير استفاده مى كنـد. نتايج حاصل از ايـن روش معمــولا انطبـاق مناسـبى بــا لبههاى عوارض تصويرى ندارند و از نظر محاسباتى نيـز

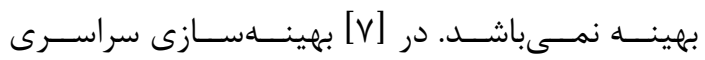

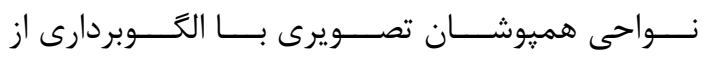

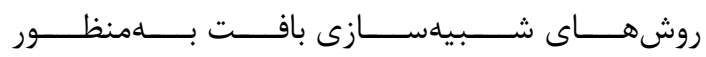
توليد سويرييكسل هاى فشرده و داراى درجه خاكسترى ثابت معرفى شده است.

از ديكر روشهاى شناختهشده براى توليد سوير بيكسـل

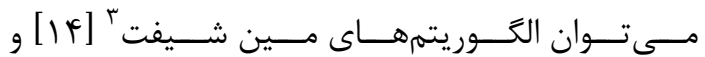

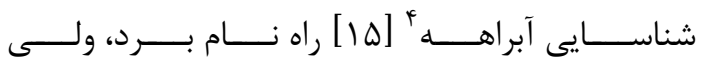

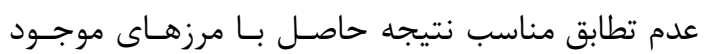

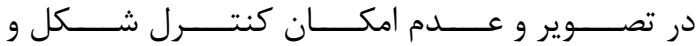

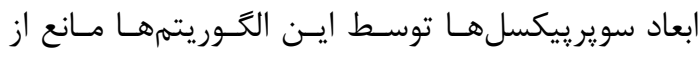

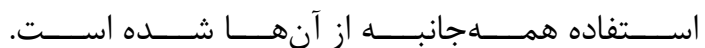

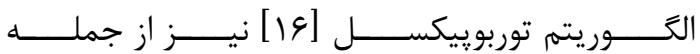
الخوريتمهاى معرفىشده بهمنظور توليد سويرييكسلهـا است. اين روش مبتنى بر بسط دادن تعدادى نقاط بـــر

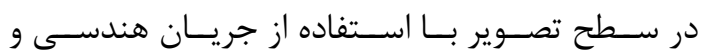

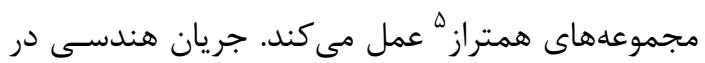

\footnotetext{
${ }^{1}$ Localization

${ }^{2}$ Normalized cut

${ }^{3}$ Mean-shift

${ }^{4}$ Watershed

${ }^{5}$ Level set
} 


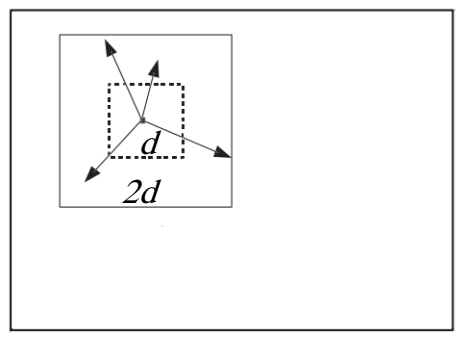

محدوده جستوجو در الكوريته SLIC

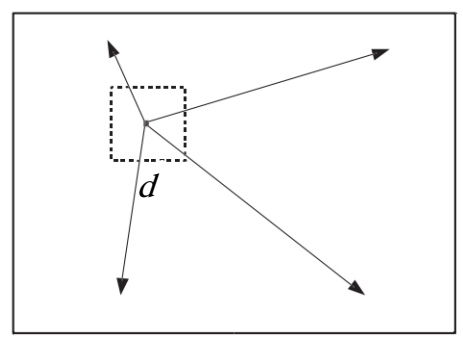

k-means محدوده جستوجو در الغَوريتم

شكل ا : تفاوت ينجره جستوجو در دو الخَوريتم SLIC و k-means

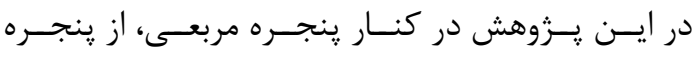

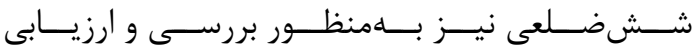

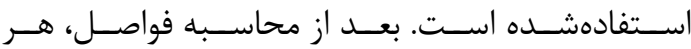
ييكسل به نزديكترين سوير ييكسل منتسـب مسىشـود.

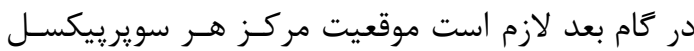

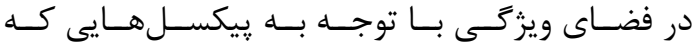

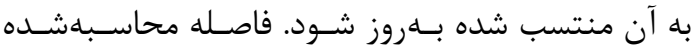

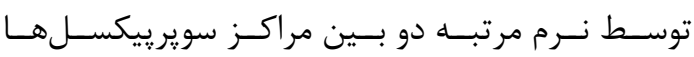

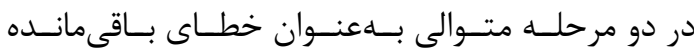

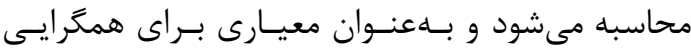
جرخه تكرارى الخوريتم در نظر گرفته مىشود.

بهاينترتيب ملاحظه شد كه الكوريتم SLIC مشابه يك الكوريتم خوشهبندى در يك فضاى ويزَّى ينجبعـدى و در يك فضاى مكانى محدودشده عمل مى كند. بنـابراين

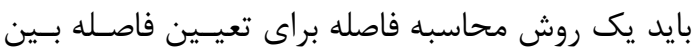
هر ييكسل تا مراكز سوير ييكسلها تعريف كرد. بلهنظور رعايت استحكام در محاسبات مربوط به فاصله با توجـهـ به همرجنس نبودن المانهاى فضاى ويزگى تعريف شده، فاصله بهصورت مجزا بهصورت زير براى اطلاعات رنتىى
در اين الكوريته يك فضاى ويزگى ينج بعدى متشكل از

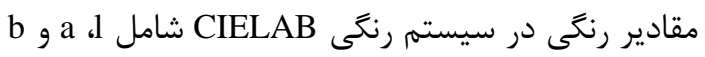
به همراه مقادير حـاوى اطلاعـات مكـانى مركـز خوشـهـ در سطح تصـوير (r, c) مـورد اسـتفاده قـرار مسى يـيـرد.

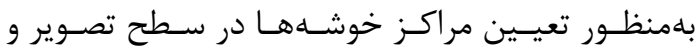
با هدف توليد سوير بيكسل هاى با انـدازه تقريبـا مشـابه،

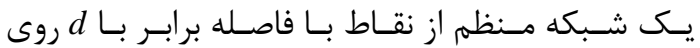

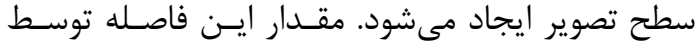
رابطه ( (1) محاسبه مىشود:

$$
d=\sqrt{P / n} \text { رابطه (1) }
$$

در اين رابطه P تعداد קِيكسـلهــاى موجـود در تصـوير

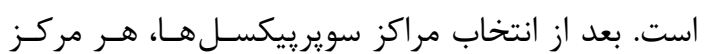

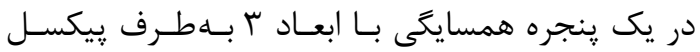

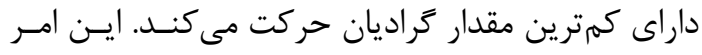

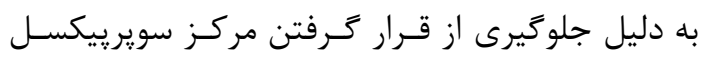
بر روى لبههاى تصوير و يا پِيكسلهاى نويزى است. كام بعدى الكَوريتم انتساب هر يُكسل به سوير ريكسلى

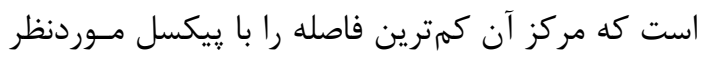
دارد. اندازهگيرى فاصله در اين مرحله تفاوت اصلى بين

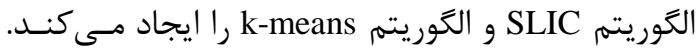

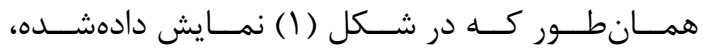

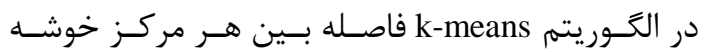

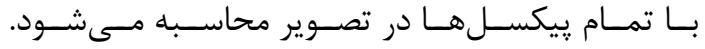
در الكَوريتم SLIC بهمنظور كاهش حجـم محاسـبات و و بدون كاهش كار آيى الكوريتم، فاصله مراكز خوشههــا بـا קيكسلها در يك همسايكى يِيرامون مركز سوير ريكسل

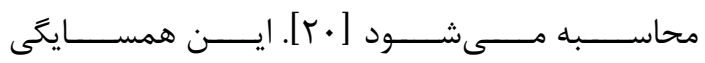

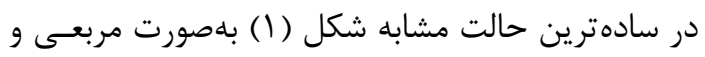

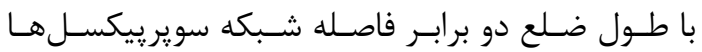
تعريف مىشود.

representations include the CIE 1994 color space and the CIE 2000 color space. 


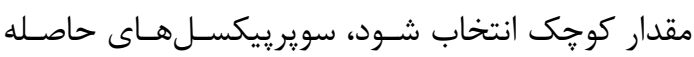

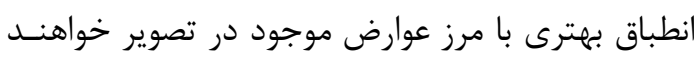

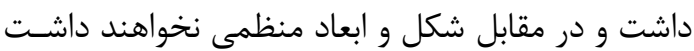

$[r \cdot]$

r

DBSCAN

با توجه به اينكه سوير بيكسل ها را مىتوان بهمثابه يـك تصكي

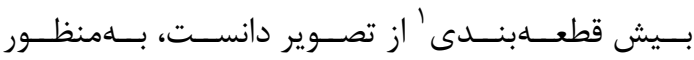

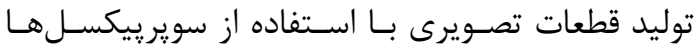

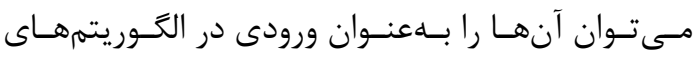

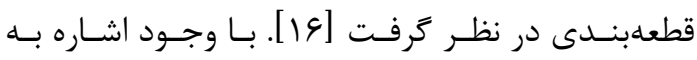

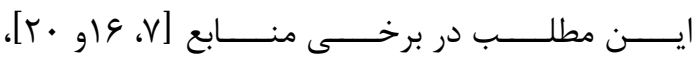

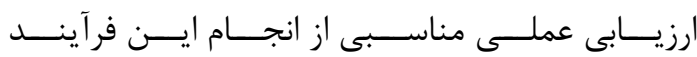

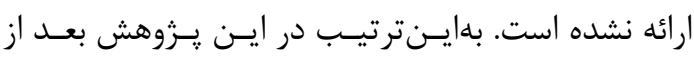

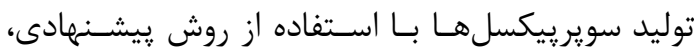
از يكى روش خوشهبندى مبتنسى بـر همسـايكى مكـانى سوير ييكسل ها تحت عنوان

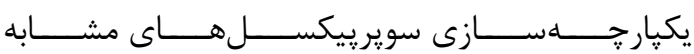
در يـك همسـايكى و توليـــ قطعـات تصـويرى مشـابه روشهاى قطعهبندى استفاده مىشود.

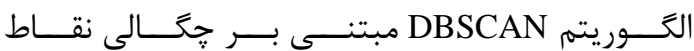

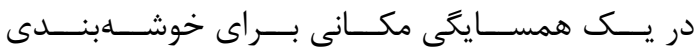

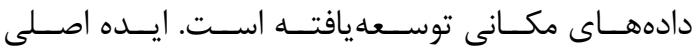

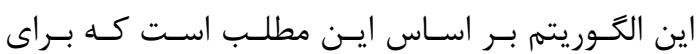

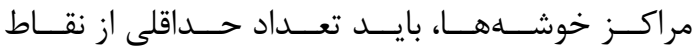

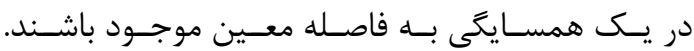

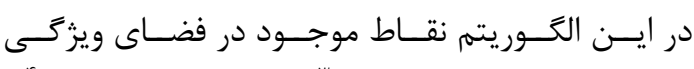

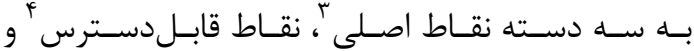

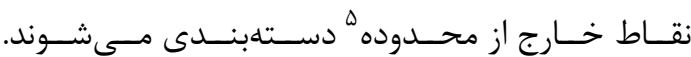

\footnotetext{
${ }^{1}$ Over-segmentation

${ }^{2}$ Density-based spatial clustering of applications with noise

${ }^{3}$ Core points

${ }^{4}$ Reachable points

${ }^{5}$ Outlier
}

و اطلاعات مختصاتى ييكسلها در فضاى تصوير مطـابق روابط (זو r) محاسبه مىشود.

رابطه (r)

$$
\begin{aligned}
& d_{c}=\sqrt{\left(l_{j}-l_{i}\right)^{2}+\left(a_{j}-a_{i}\right)^{2}+\left(b_{j}-b_{i}\right)^{2}} \\
& d_{s}=\sqrt{\left(r_{j}-r_{i}\right)^{2}+\left(c_{j}-c_{i}\right)^{2}} \quad \text { (r) }
\end{aligned}
$$

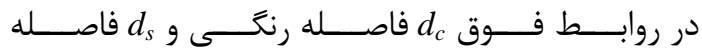

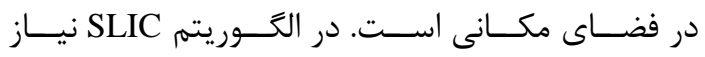

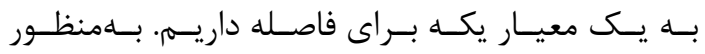

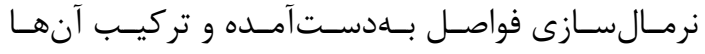
بلهصورت يك معيار معين از حداكثر مقدار ممكن بـراى

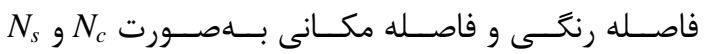
استفاده مى كنيه. بهاينترتيب معيار فاصله توسط رابطه (أ) (l) محاسبه مىشود:

$$
D=\sqrt{\left(\frac{d_{c}}{N_{c}}\right)^{2}+\left(\frac{d_{s}}{N_{s}}\right)^{2}}
$$

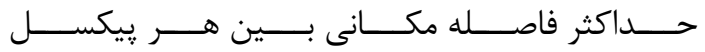

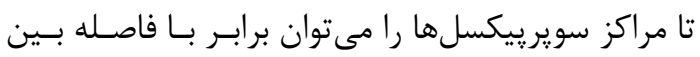

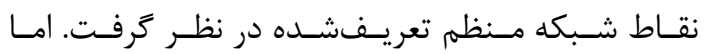
تعيين حداكثر فاصـله رنغـى كـار سـادهاى نيسـت و از

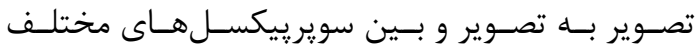
ممكن است مقادير آن متفاوت باشد. اكر در رابطــهـهـ بـالا

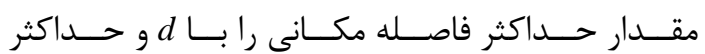

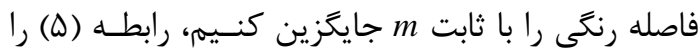

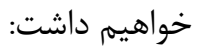

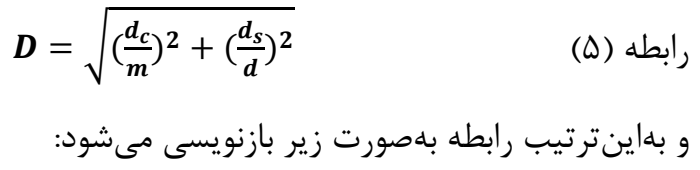
$\begin{array}{ll}D=\sqrt{\left(d_{c}\right)^{2}+\left(\frac{d_{s}}{N_{s}}\right)^{2} m^{2}} & \text { (६) }\end{array}$ در محاسبه معيار فاصـله بـهـ شـكل اخيـر نسـبت را مىتوان بهعنوان ضريب وزن در نظر ترفت. با افزايش

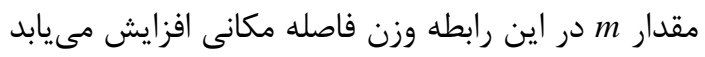

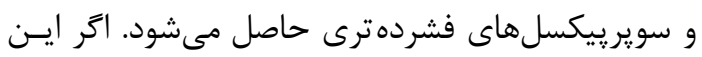


قرار بخَيرد. در ادامه الكوريتم، همه نقاطى كـهـ از نقطـهـ

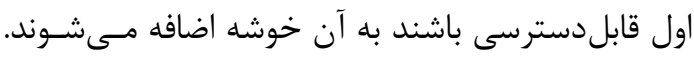
نقاط غير اصلى كه در يك خوشه قرار بخيرنـد بـهـمثابـهـ

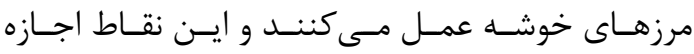

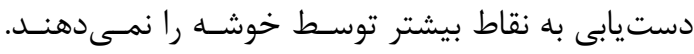

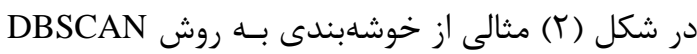

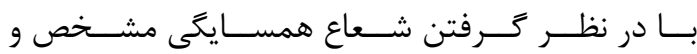

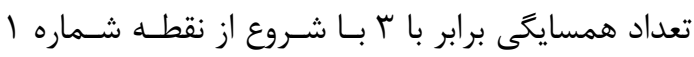

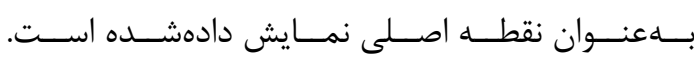

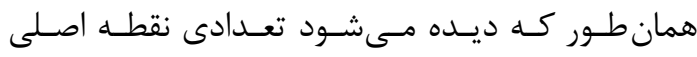

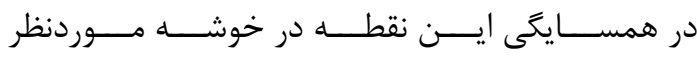

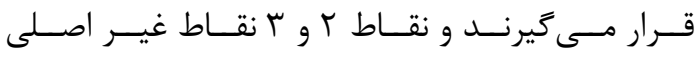

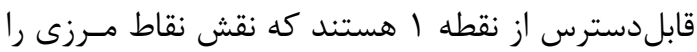

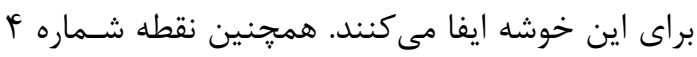

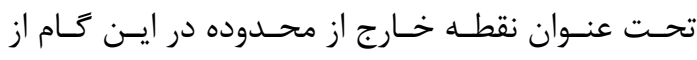
اجراى الكوريتم از خوشه موردنظر بيرون مىماند.
نقاط اصلى در اين الكوريته شامل نقــاطى هسـتند كـهـ

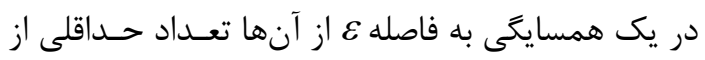

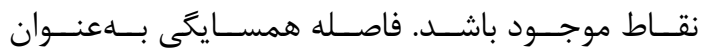

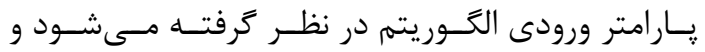

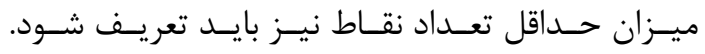

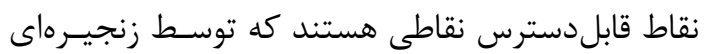

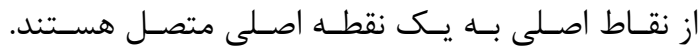

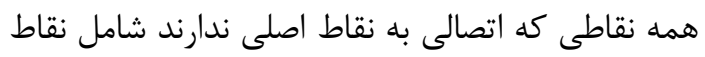
خارج از محدوده خواهند بود [Ir].

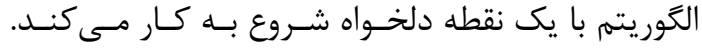

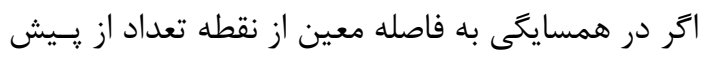

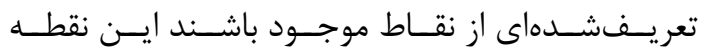

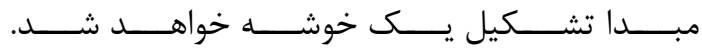

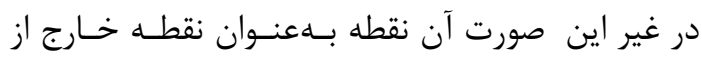

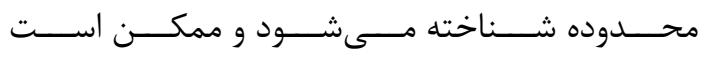
توسط ساير خوشهها مجددا شناسايى و در يـك خوشـهـ

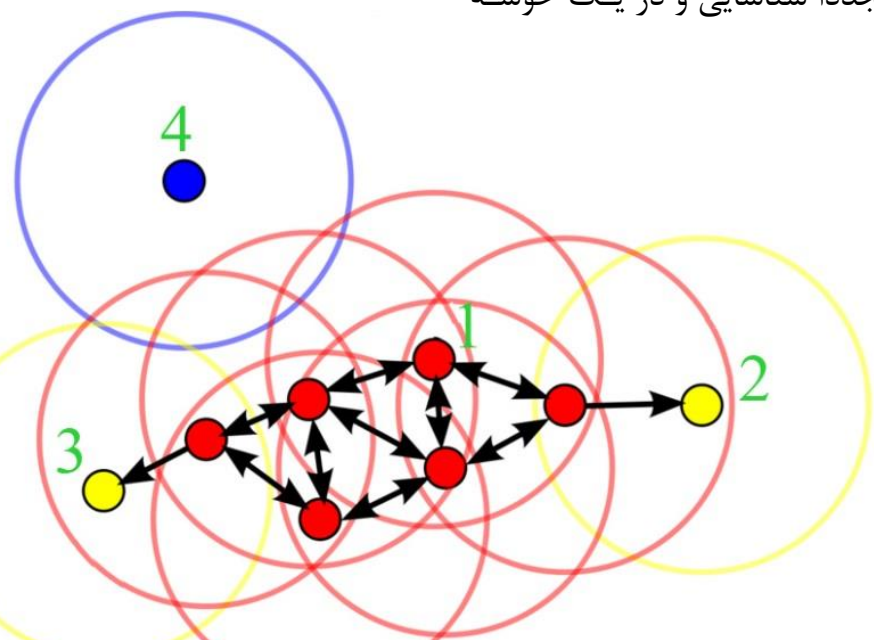

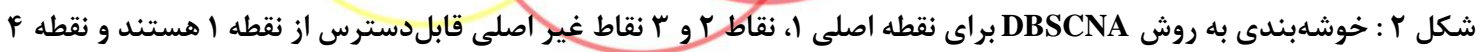

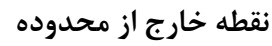

از سه دسته روشهاى ارزيابى بصرى'، نظـارتشـهـ و و

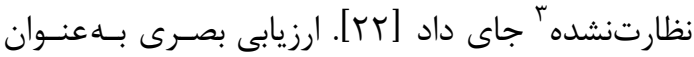

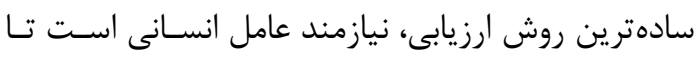

\footnotetext{
${ }^{1}$ Visual

${ }^{2}$ Supervised

${ }^{3}$ Unsupervised
}

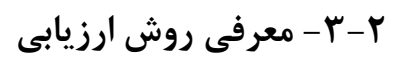

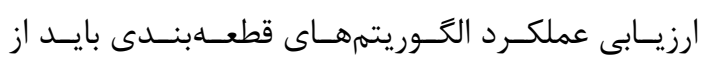

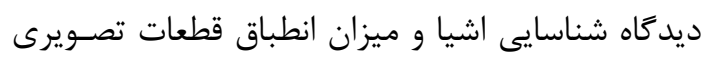

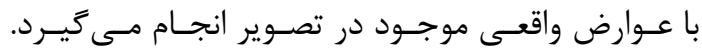

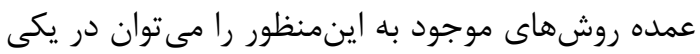




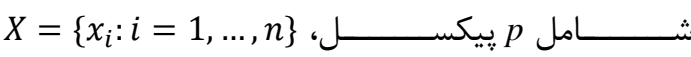
شامل مجموعه n قطعه تصويرى مرجع بـراى تصـوير و

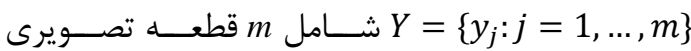
در تصوير قطعهبندى شده باشند، معيارهاى كسمادغـام و بيشادغام به شكل زير تعريف مىشوند باشند [عبارهائ:

(V) رابطه

underMerging $_{i j}=\frac{\operatorname{area}\left(x_{i}\right)-\operatorname{area}\left(x_{i} \cap y_{j}\right)}{\operatorname{area}\left(x_{i}\right)}$,

رابطه (ᄉ)

overMerging $_{i j}=\frac{\operatorname{area}\left(y_{j}\right)-\operatorname{area}\left(x_{i} \cap y_{j}\right)}{\operatorname{area}\left(x_{i}\right)}$,

$$
\boldsymbol{y}_{j} \in \boldsymbol{Y}_{\boldsymbol{i}}^{*}
$$

منظور از

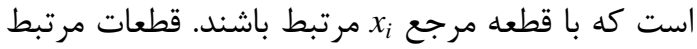

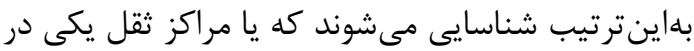

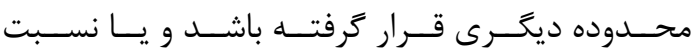
سطح مشترك به سطح يك قطعه بزركتر از ها • باشد.

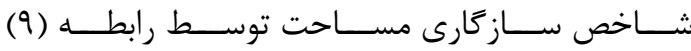

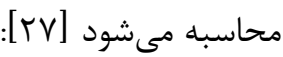

$$
A F I_{i}=\frac{\operatorname{area}\left(x_{i}\right)-\operatorname{area}\left(y_{i M a x}\right)}{\operatorname{area}\left(x_{i}\right)}
$$

(9)

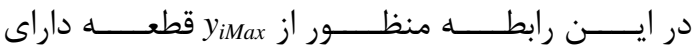

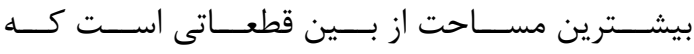

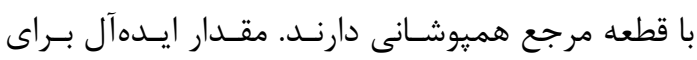
اين معيارها برابر با صفر است.

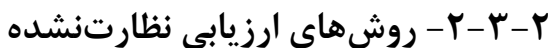

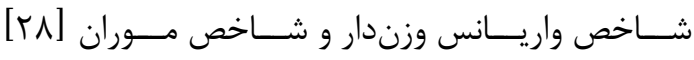
معيارهاى نظارت نشده مـورد اسـتفاده در ايسن يـرؤهش

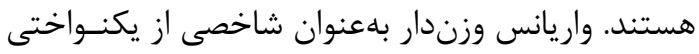

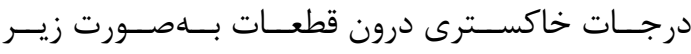
$W v=\frac{\sum_{i=1}^{n} a_{i} v_{i}}{\sum_{i=1}^{n} a_{i}}$

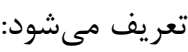

در اين رابطه كه براى يك تصوير قطعهبندىشده شامل

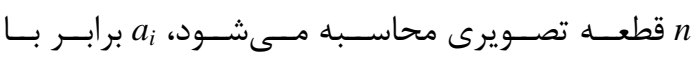

با توجه به بيشفرضهاى ذهنى عمل مقايسه بين نتايج

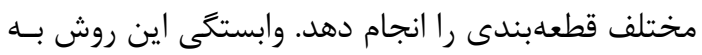

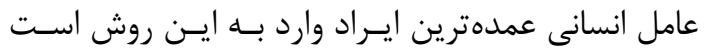

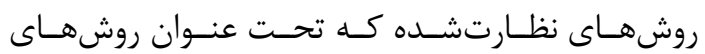

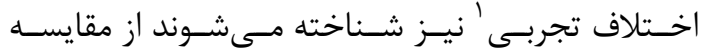

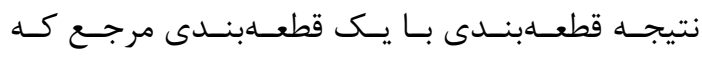

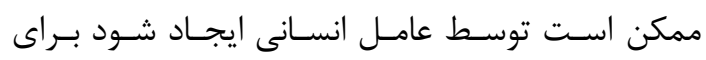

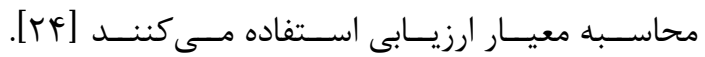

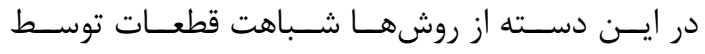

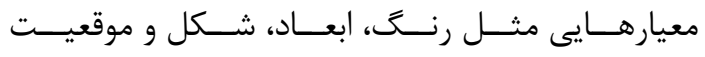

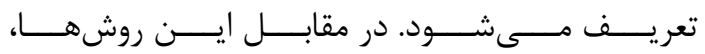

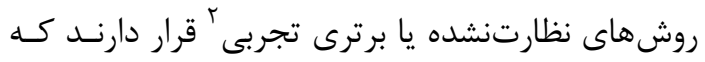

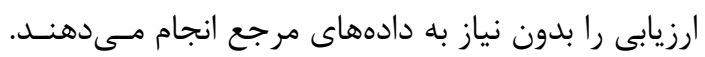

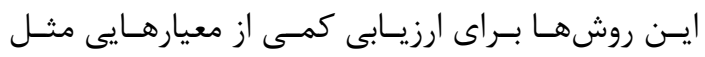

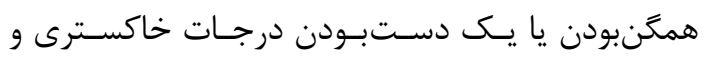

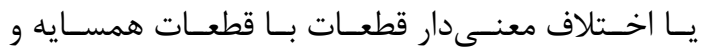

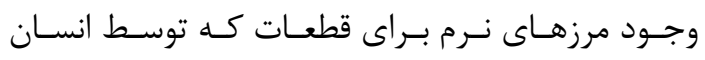

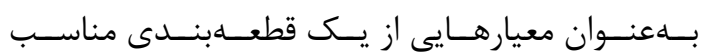

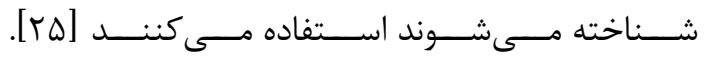

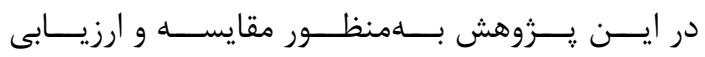

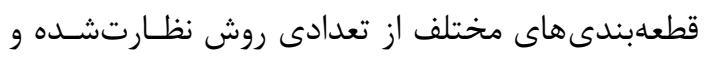

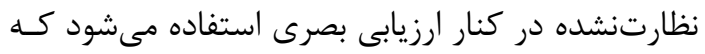

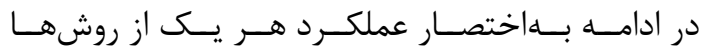
تشريح مىشود. r-r-1-1 - روشهاى ارزيابى نظارتشده

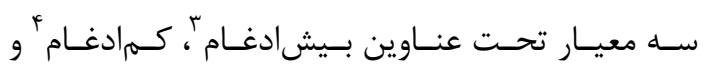

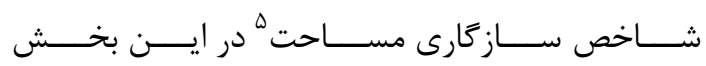

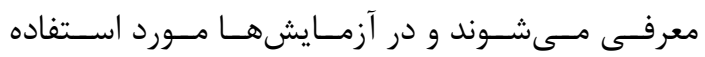

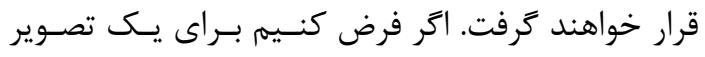

${ }^{1}$ Empirical discrepancy

${ }^{2}$ Empirical goodness

${ }^{3}$ Over merging

${ }^{4}$ Under merging

${ }^{5}$ Area fit index 
مورد استفاده قرار خواهد كرفـت. مجموعـهـ اول توسـط جامعه بينالمللى فتوكرامترى و سنجشازدور ' بهمنظور

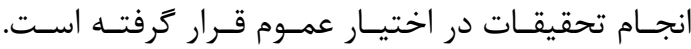
اين مجموعه داده شامل تصاويرى با توان تفكيك مكانى

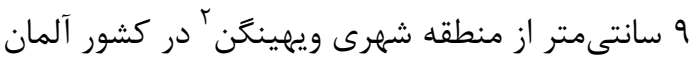

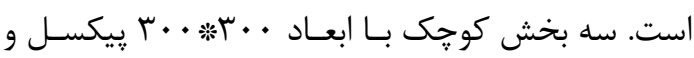

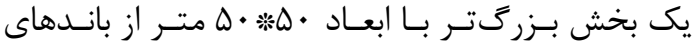

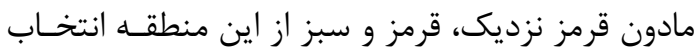
شده و مورد استفاده قرار خواهند ترفت.

مجموعه داده دوم باندهاى مرئى اخذشده توسط بِهيـاد

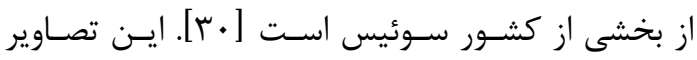

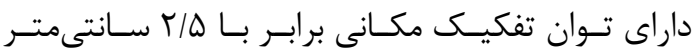

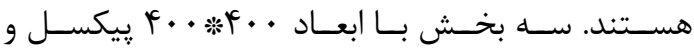

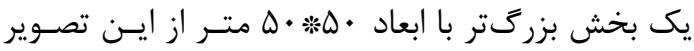

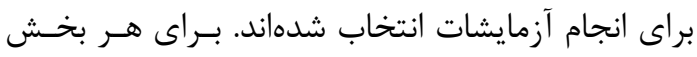

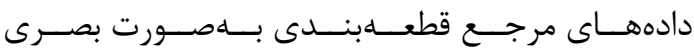
توليد شده است. در شكل (r) تصوير مناطق منتخب از آناز

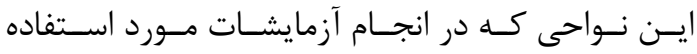

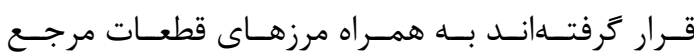
نمايش دادهده است.

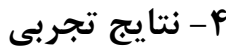
در اين يزوهش آزمايشات تحت سه سـناريوى مختلـف

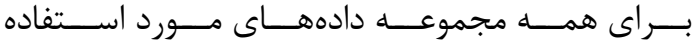

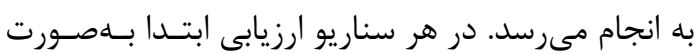
بصرى و سيس بهصورت كمى و به دو شكل نظارتشده إنها و نظارتنشده انجام خواهد كرفت. سناريوى اول شـامل

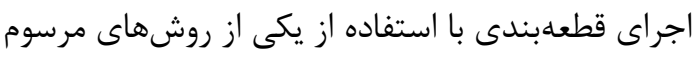

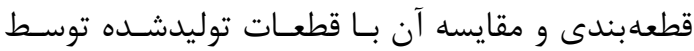
روش بيشنهادى و الكوريتم سويرييكسل است.

\footnotetext{
${ }^{1}$ International society for photogrammetry and remote sensing (ISPRS)

${ }^{2}$ Vaihingen
}

مساحت قطعه اسـت كـه بــهـــــوان وزن در محاسـبات

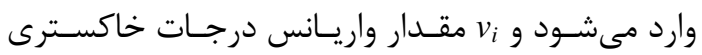

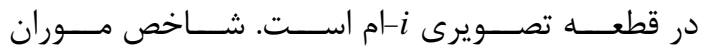

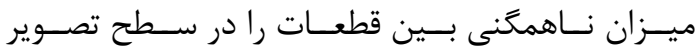

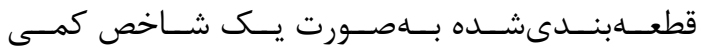

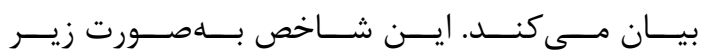
محاسبه مى شود: $M I=\frac{n \sum_{i=1}^{n} \sum_{j=1}^{n} w_{i j}\left(g_{i}-\bar{g}\right)\left(g_{j}-\bar{g}\right)}{\left(\sum_{i=1}^{n}\left(g_{i}-\bar{g}\right)^{2}\right)\left(\sum_{i \neq j} w_{i j}\right)} \quad$ (l) در اين رابطـهـ $g_{i}$ ميـانكَين درجـات خاكسـترى مربـوط

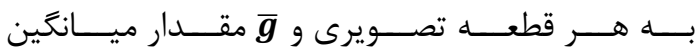

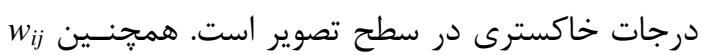

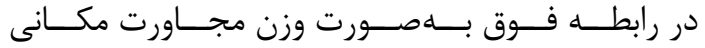
تعريف مىشود. مقدار اين يـارامتر بـراى قطعـات داراى

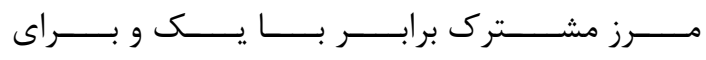
قطعات بدون مرز مشترك برابر با صفر تعريف مىشـود. مقادير كوجكتر بهدست آمده براى اين معيارهـا معـادل يك قطعهبندى موفق در مقابل ساير روشها مىباشد. ץ- مجموعه دادههاى تصويرى مورد استفاده توان تفكيك مكانى بالا در تصاوير سنجشازدورى باعث باعث كاهش ابعاد يِيكسلها در مقايسه با عـوارض موجـود در

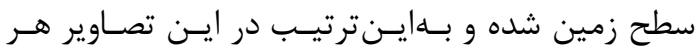

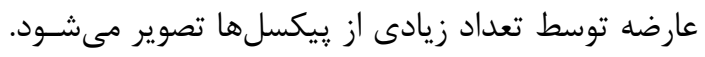

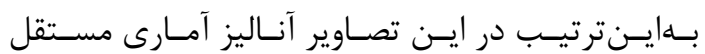

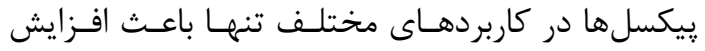

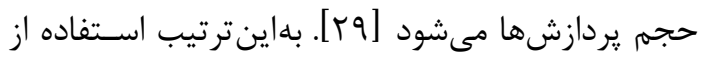

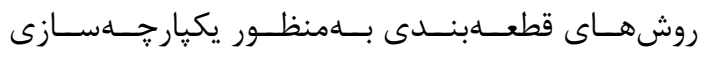
ريكسلهاى مشابه و استفاده در يـردازشهـاى آتسى در اين تصاوير امرى اجتنابنايذير است.

در اين يزوهش از تصاوير بـا تـوان تفكيـك مكـانى بــالا

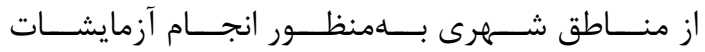

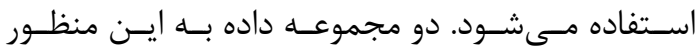



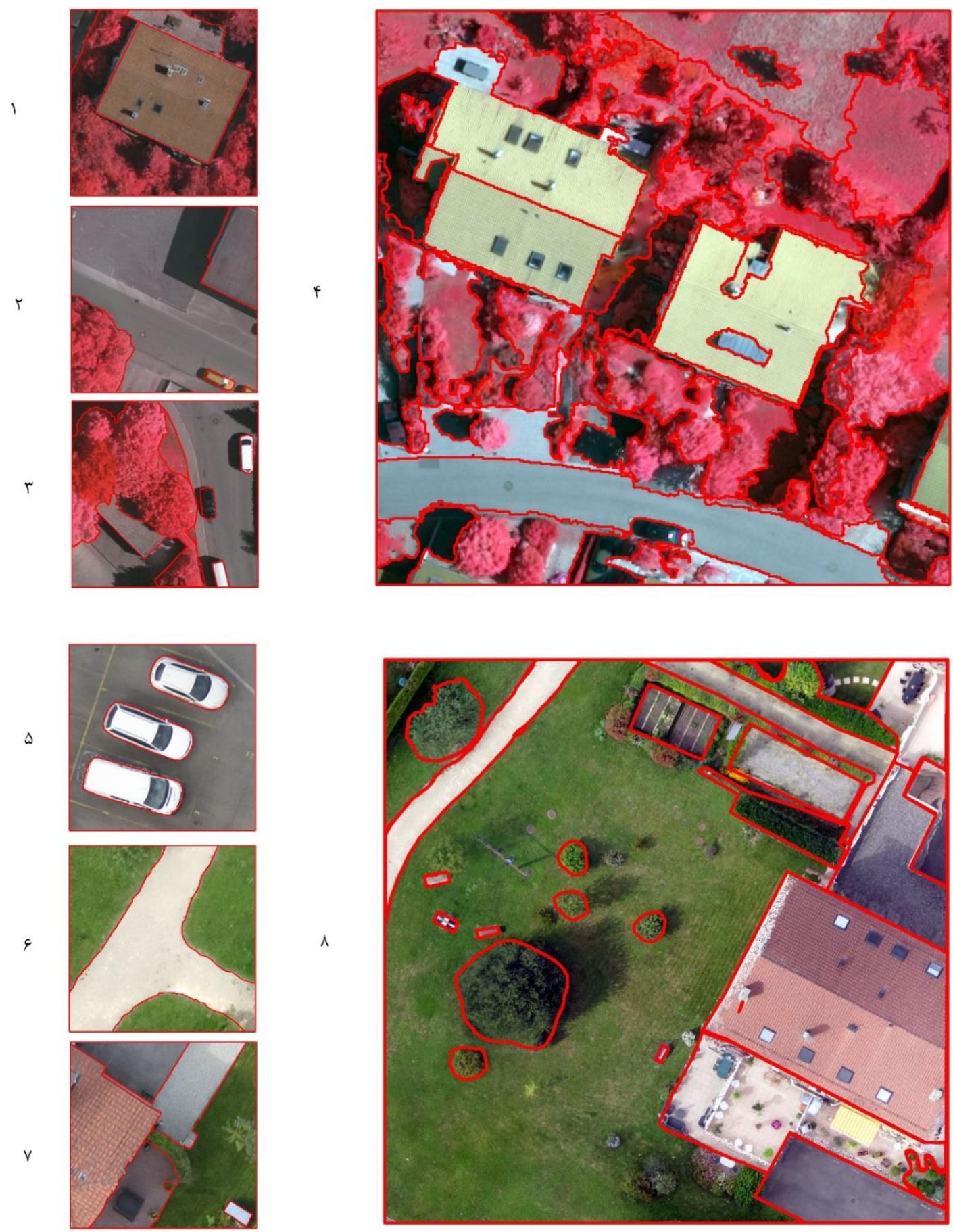

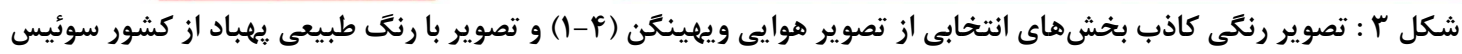

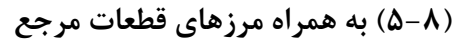

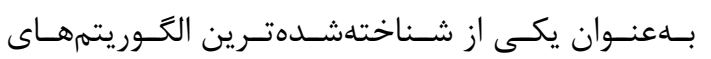

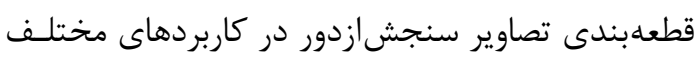

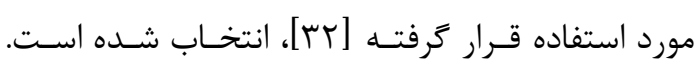

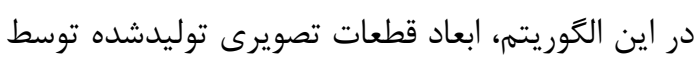

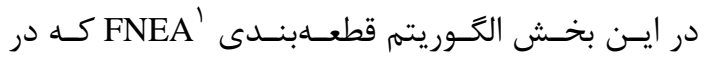

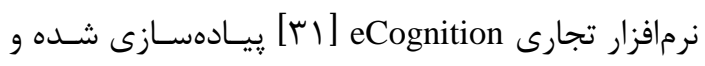

${ }^{1}$ Fractal net evolution approach 
يــارامتر مقيــاس و تعيــين نـــرخ تغييــــات مقـــادير

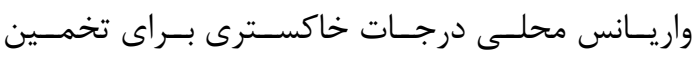
ضريب مقياس مناسب اسـتفاده مسىشـود. نتـايج بــراى دراى

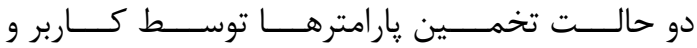

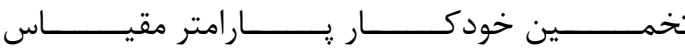

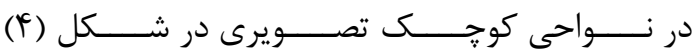

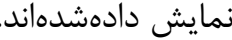

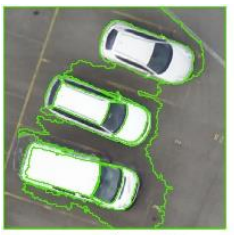

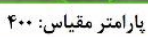

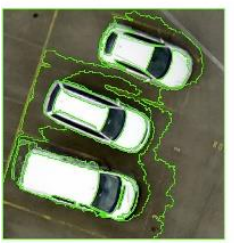

بارامتر مقياس: PAV

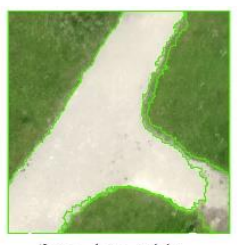

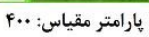

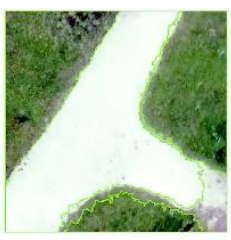

Fهارامتر مقياس: FAF

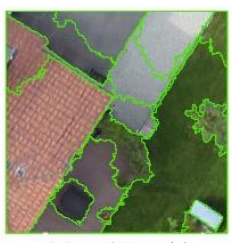

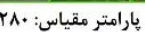

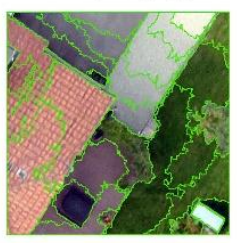

بارامتر مقياس: ..1

يـارامتر مقيــاس كنتــرل مسىشـود. بــراى هـــر تصـوير

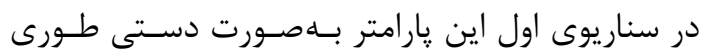
تنظـيم شـده كـه بهتـرين قطعـات تصـويرى بــا توجـهـ

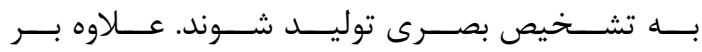

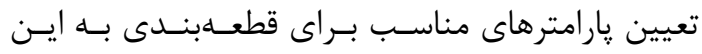
روش، از يك روش خودكار نيز بهمنظور تعيـين يـارامتر

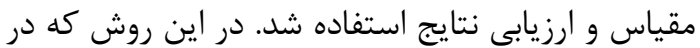

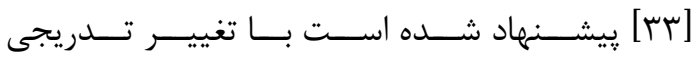

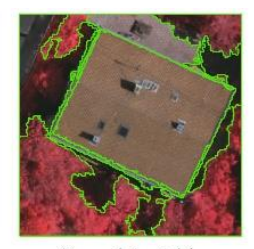

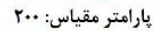

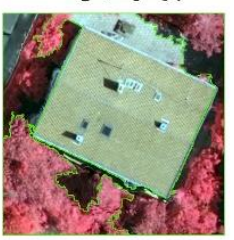

يارامتر مقياس: rاس

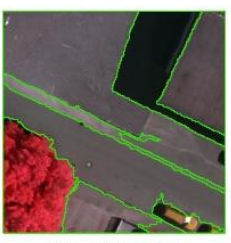

بارامتر مقياس: ب. باس

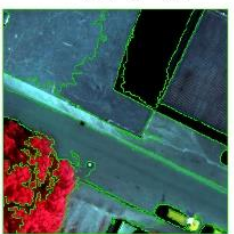

بارامتر مقياس: f.

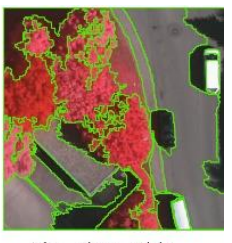

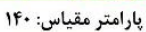

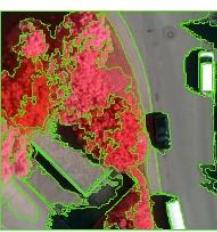

بارامتر مقياس: F+F

شكل ₹ : نتيجه قطعهبندى با استفاده از الكَوريتم FNEA براى تصاوير مورد استفاده در انجام آزمايشات (رديف بالا انتخاب يارامتر توسط كاربر و رديف پإيين انتخاب خودكار هارامتر مقياس)

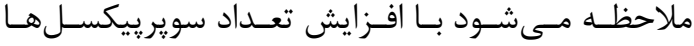

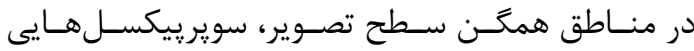

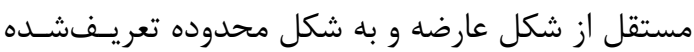

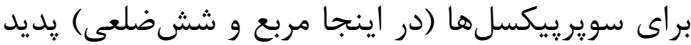

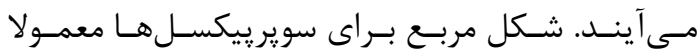

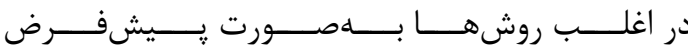

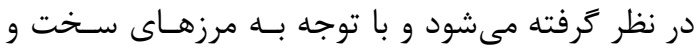

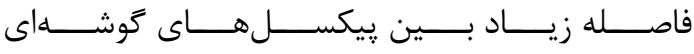

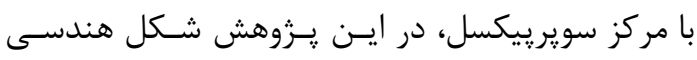

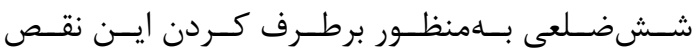

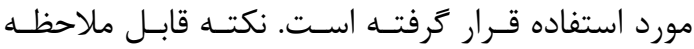

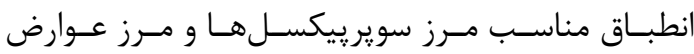

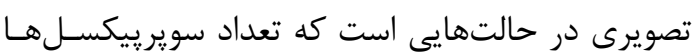
بيشتر از حداقل مورد نياز در نظر كرفته شوند.

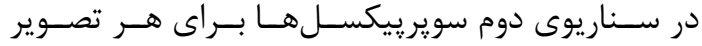

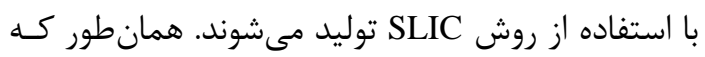

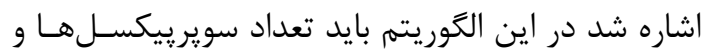
وزن فاصله مكانى در برابـر فاصـله رنغـى تنظـيمه شـود.

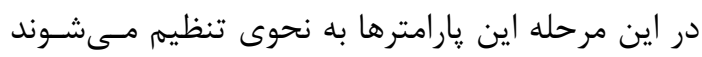

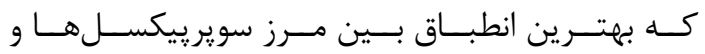

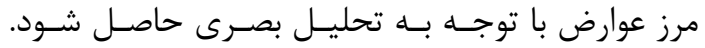

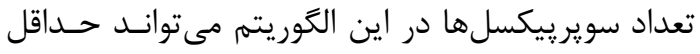

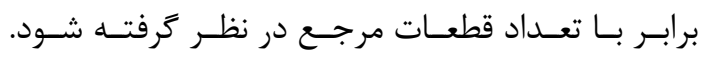

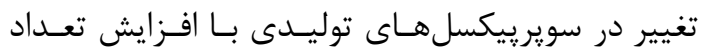

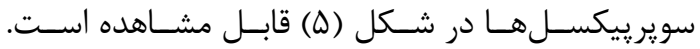

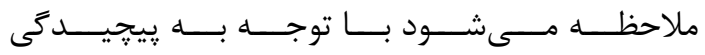
در شكل عوارض موجود، تعداد حداقل سويرييكســهــا

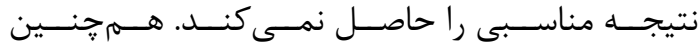




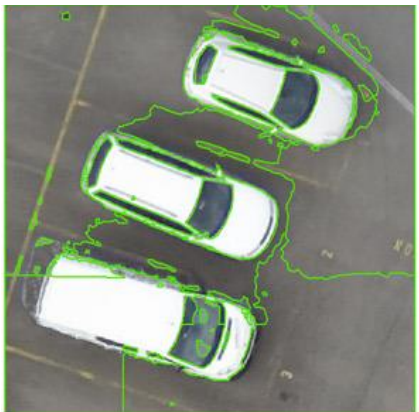

تعداد سوير קييكسل مربعى: F

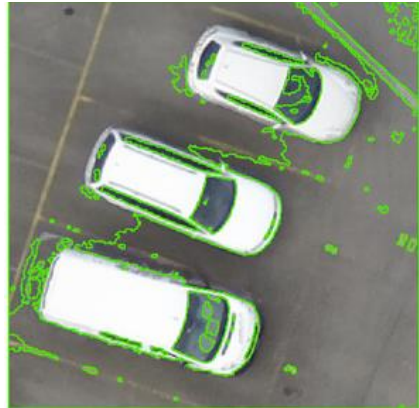

تعداد سوير קييكسل ششضلعى:

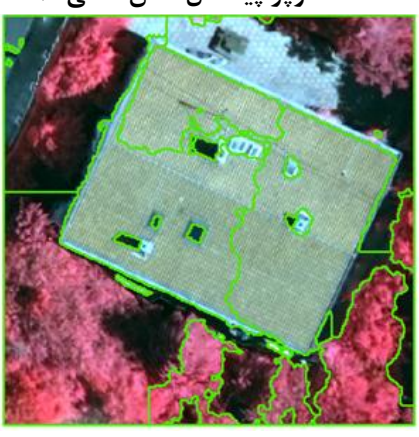

تعداد سوير קييكسل مربعى:

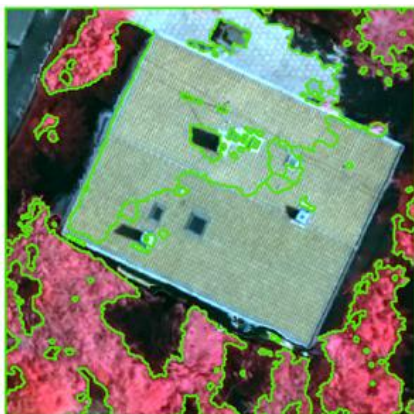

تعداد سوير קِيكسل ششضلعى

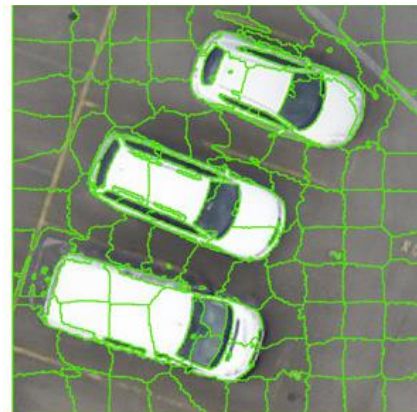

تعداد سوير پِيكسل مربعى: ..1

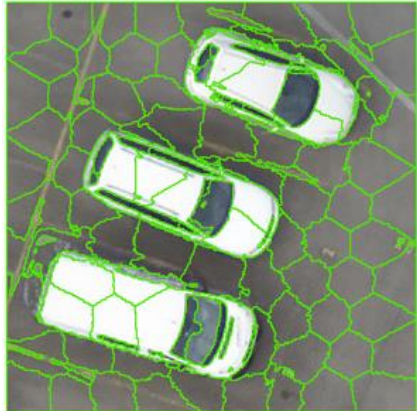

تعداد سوير بِيكسل ششضلعى: •.1

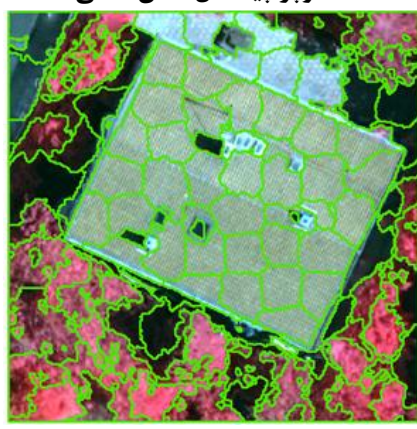

تعداد سوير ييكسل مربعى: +.1

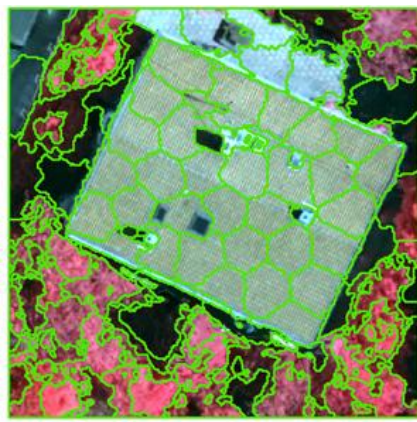

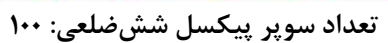

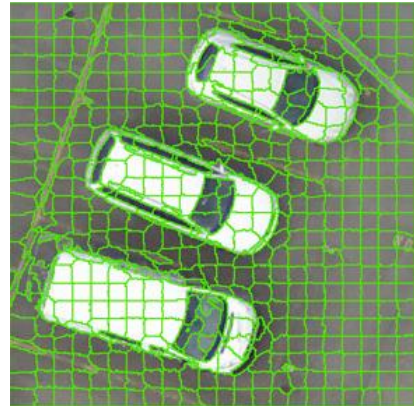

تعداد سوير بيكسل مربعى: ••ه

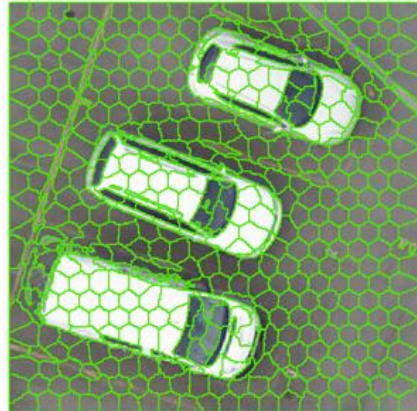

تعداد سوبر بِيكسل ششضلعى: ••ه

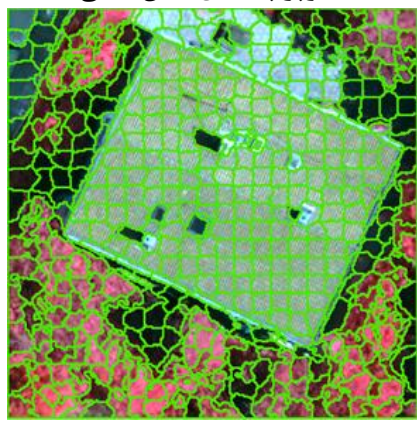

تعداد سوير وبيكسل مربعى: ••

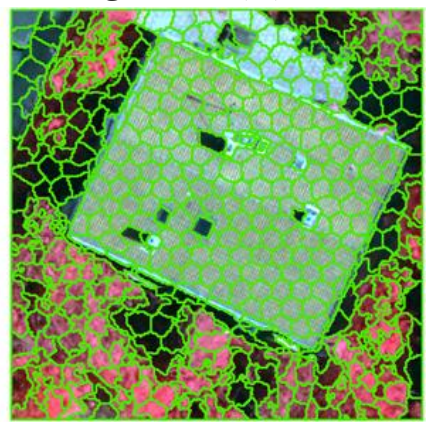

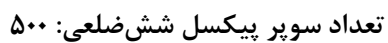

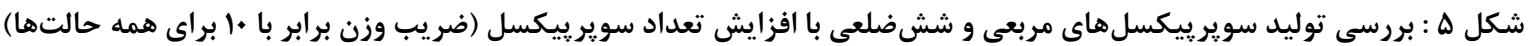

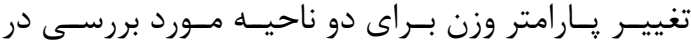

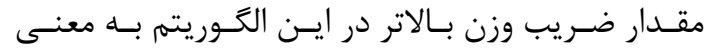

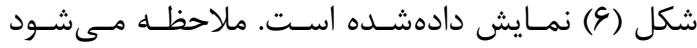

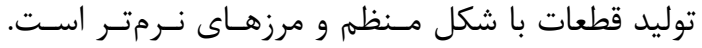

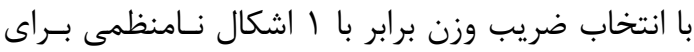

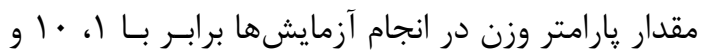

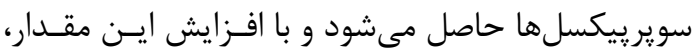

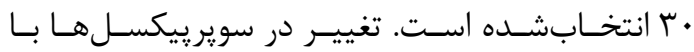




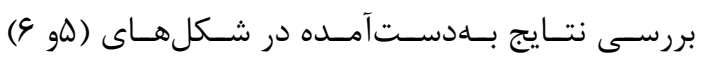
تفاوت جشم گريرى بين استفاده از سوير ييكسل مربعى و
جزئيات زائد ناشى از تغييرات محلى درجات خاكسترى

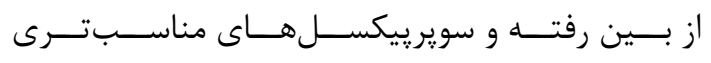

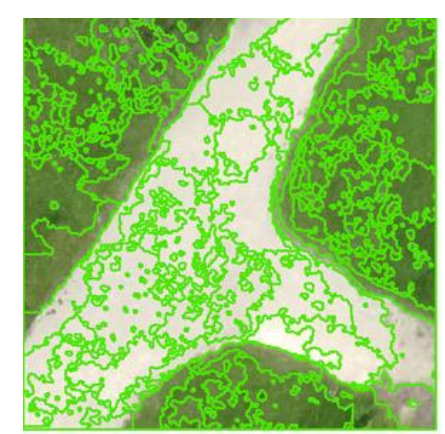

سوير بيكسل مربعى، ضريب وزن: 1

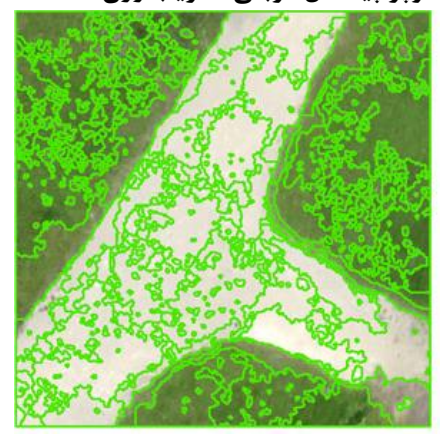

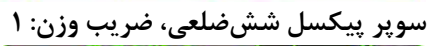

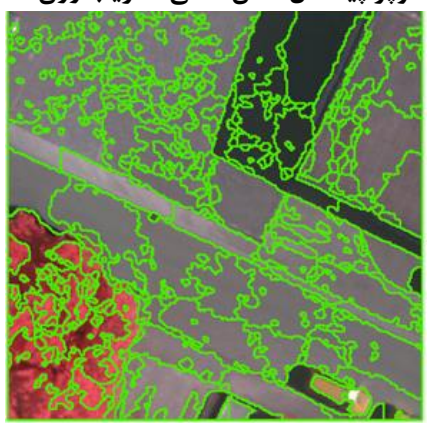

سوير بيكسل مربعى، ضريب وزن: 1

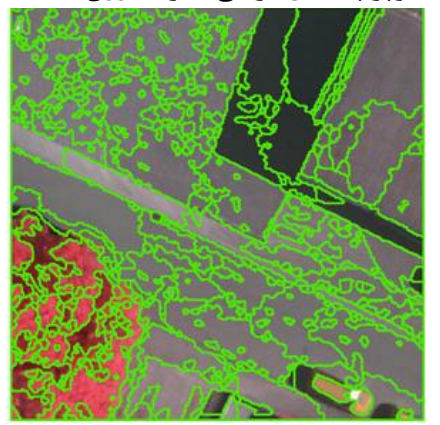

سوير بيكسل ششضلعى، ضريب وزن: 1

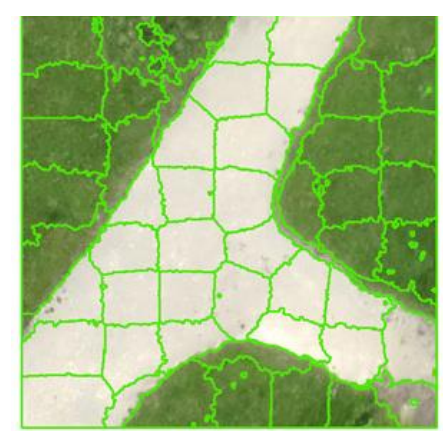

سوير بيكسل مربعى، ضريب وزن: · 1.

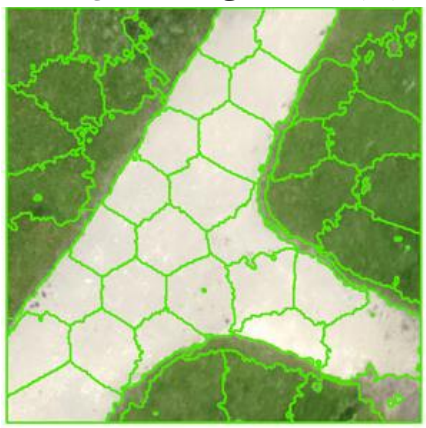

سوير بيكسل ششضلعى، ضريب وزن: +1

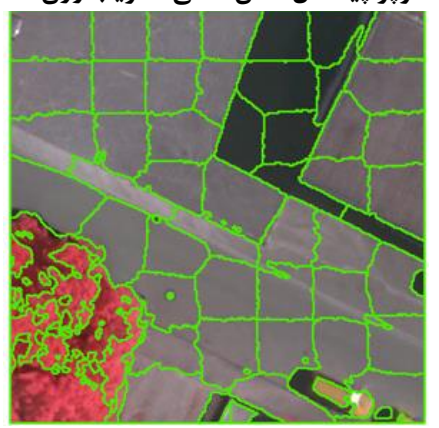

سوير بييكسل مربعى، ضريب وزن: •1

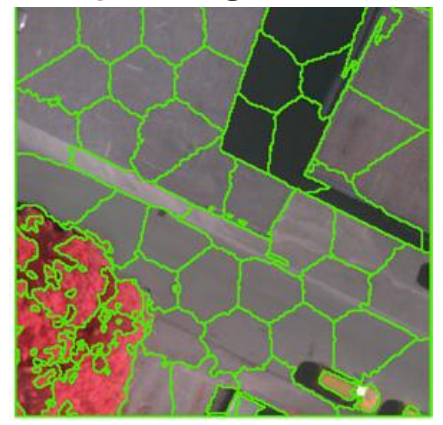

سوير پِيكسل ششضلعى، ضريب وزن: +1

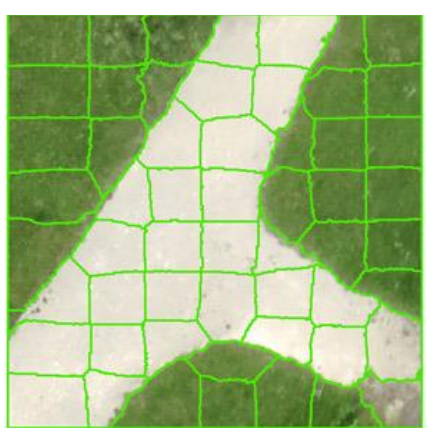

سوير يبكسل مربعى، ضريب وزن: • مب

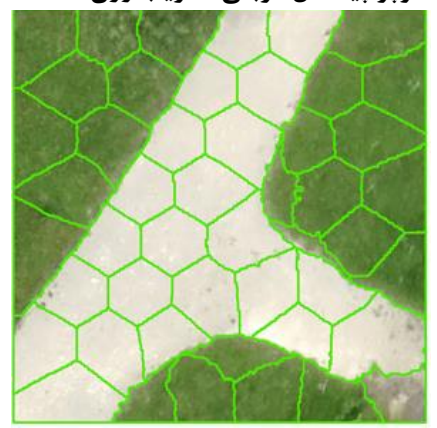

سوير ييكسل ششضلعى، ضريب وزن: •

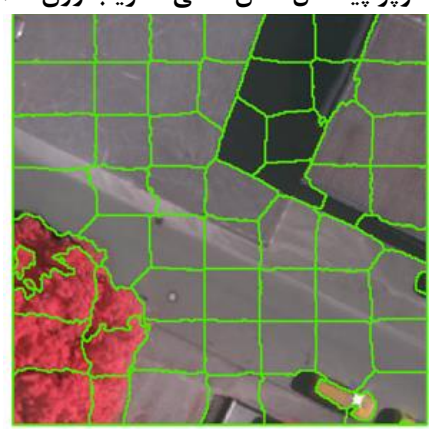

سوير ييكسل مربعى، ضريب وزن: •

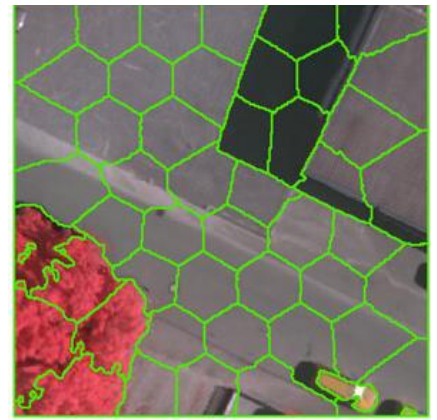

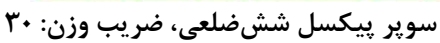

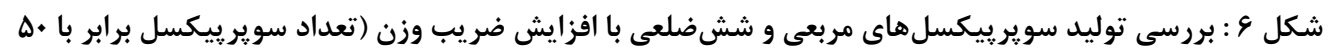

براى همه حالتها) 


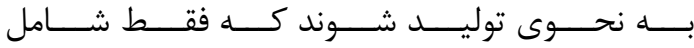

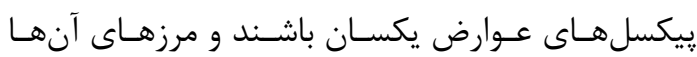

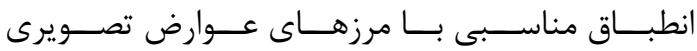

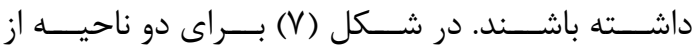
تصاوير مورد اسـتفاده در آزمايشـات قطعـات تصـويرى

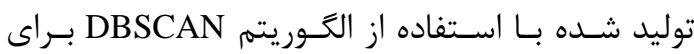
سوير ييسـكلهــاى شـششــلعى و مربعـى توليدشــده توسط الخوريتم SLIC نمايش دادهشدهاند.

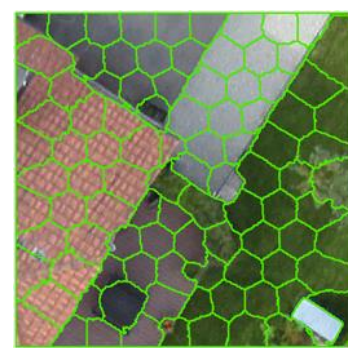

سوير يِيكسل هاى شش ضلعى

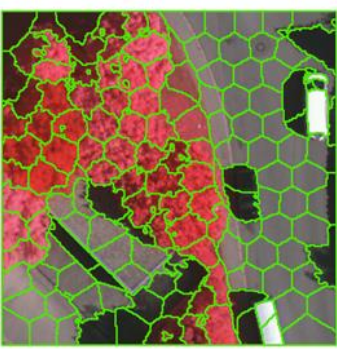

سويريكسل هاى شش ضلعى

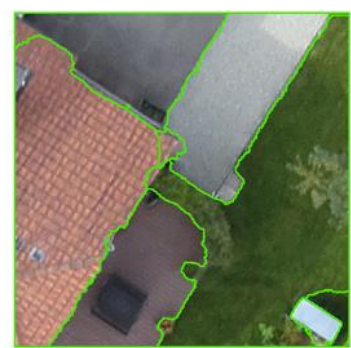

تطعات تصويرى توليدشده با استفاده از سوبر بيكسل هاى

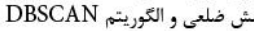

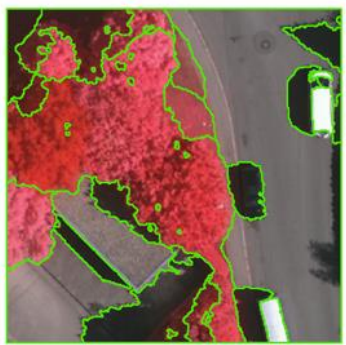

قطعات تصويرى توليدشده با استفاده از سوير بيكسل هاى

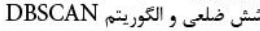

سومين سناريو شامل استفاده از الگُوريتم خوشـهبنـدى DBSCAN

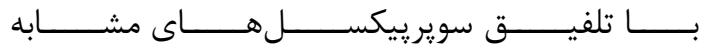
در همسايخَى هاى مكـانى اسـت. بــه ايسن منظـور ابتـدا

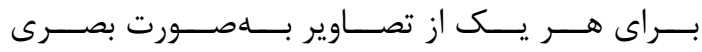

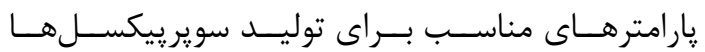

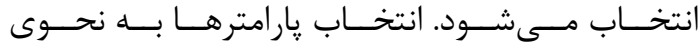

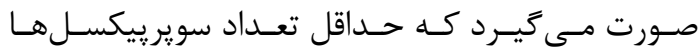
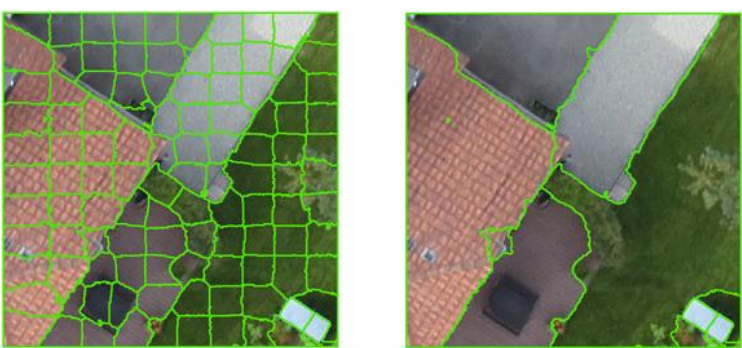

سوير ييكسل هاى حهار ضلعى

قطعات تصويرى توليدشده با استفاده از سويربيكسل هاى

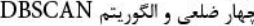
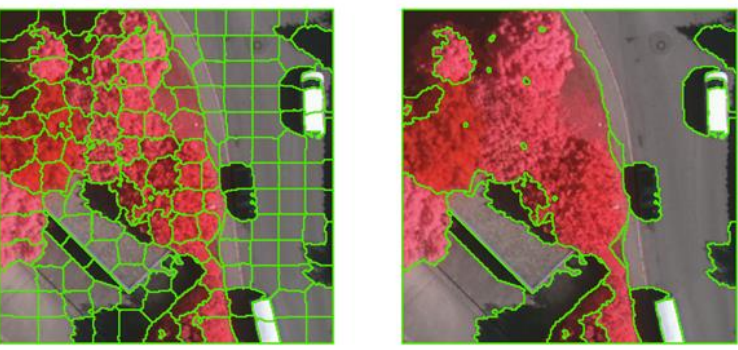

سويريكسل هاى خهار ضلعى
قطعات تصويرى توليدشده با استفاده از سويربيكسل هاى

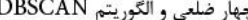

شكل V : توليد قطعات تصويرى با استفاده از سوير ييكسل هاى ششضلعى و مربعى با استفاده از الكَريتم نم براى دو تصوير نمونه

با تعيين خودكار يارامتر مقياس و همجنين اسـتفاده از

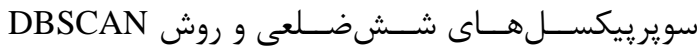

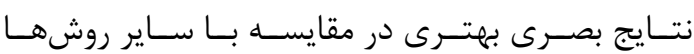
ايجاد مى كنند.
نتايج حاصل تا اين بخش بـر روى بخـشـهـاى كوجـــ تصـاوير ارائـهـ شـد. در شـكل (^) بـهـمنظــور بررسـى و

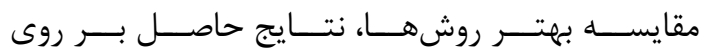

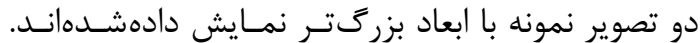
ملاحظه مى شود اسـتفاده از روش قطعـهبنـدى FNEA 


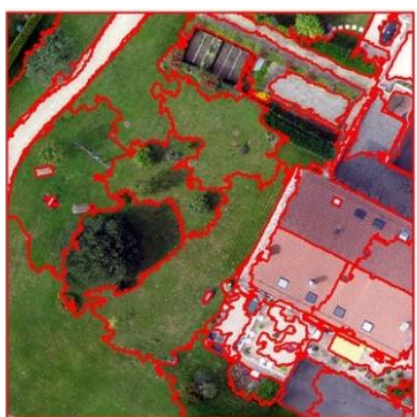

قطعهبندي به روش FNEA

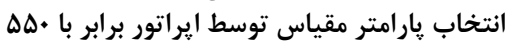
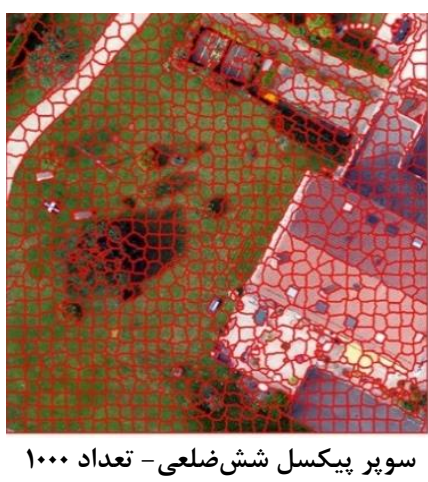

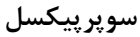

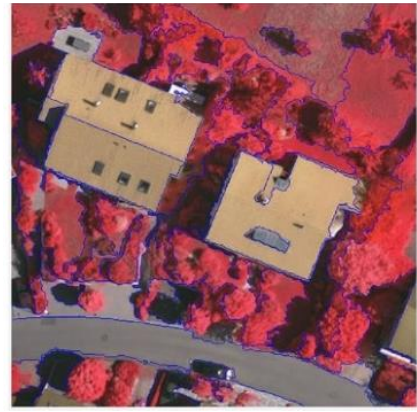

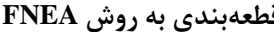

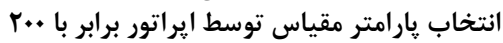

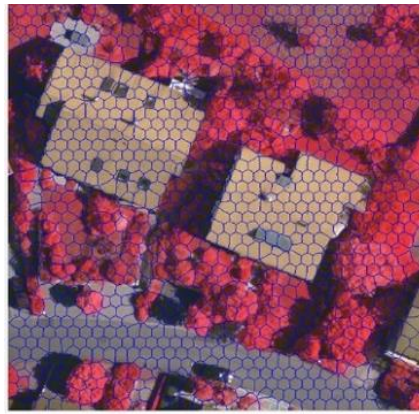

سوير يِيكسل ششضلعى - تعداد .... سوير يُيكسل

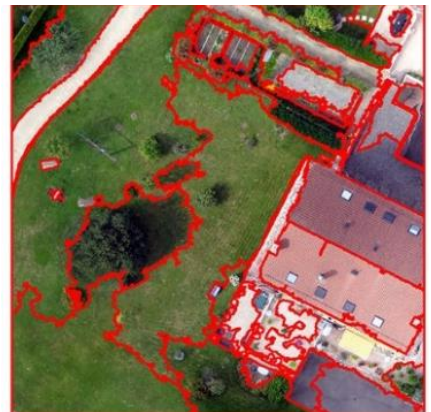

قطعهبندى به روش FNEA

انتخاب يارامتر مقياس بهصورت روش خودكار برابر با

VHr

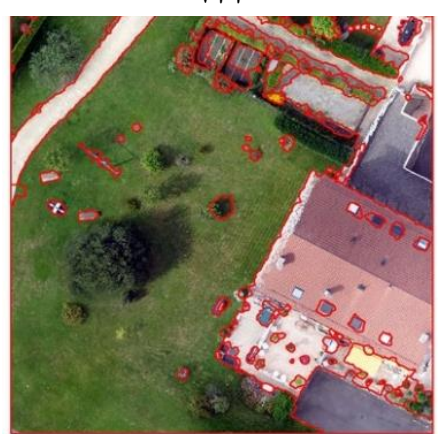

بهبود سوير بييكسل مربعى به روش DBSCAN

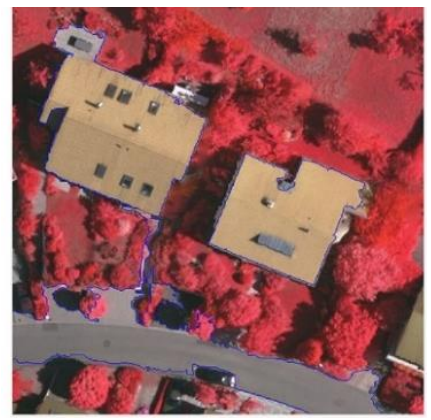

قطعهبندى به روش FNEA

انتخاب يارامتر مقياس بلهصورت خودكار برابر با GrA

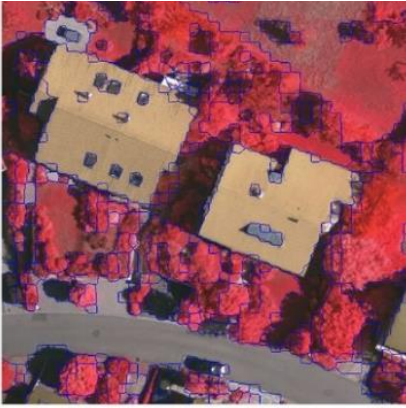

بهبود سوير ييكسل مربعى به روش DBSCAN

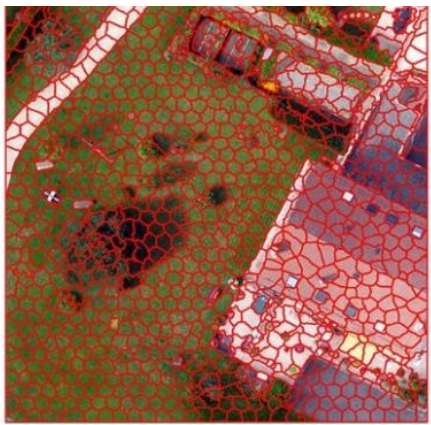

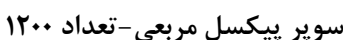

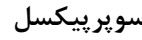

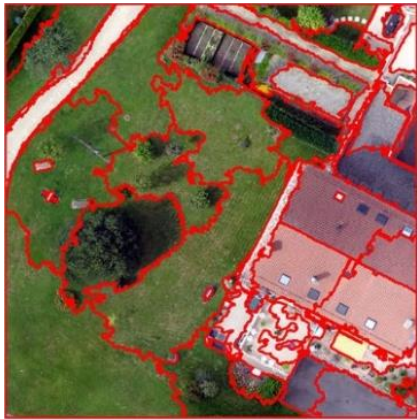

بهبود سوير بييكسل ششضلعى به روش DBSCAN

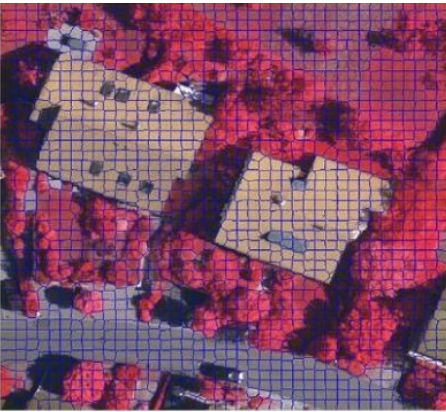

سوير ييكسل مربعى -تعداد +.19

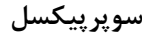

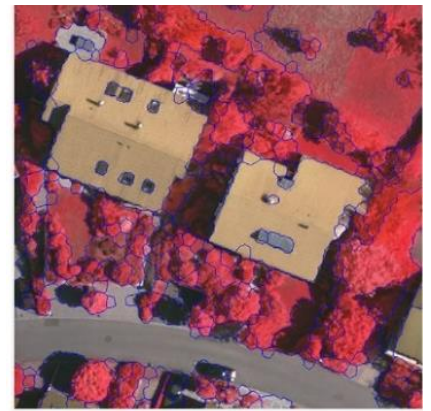

بهبود سوير بيكسل ششضلعى به روش DBSCAN

شكل ^ : نمايش نتايج بصرى بر روى تصاوير نمونه با ابعاد بزرى 
در تصوير، در مناطق همخًن تصوير، سوير ريكسلـهـايى

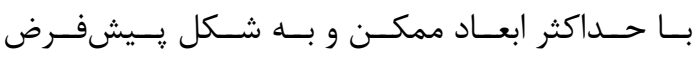

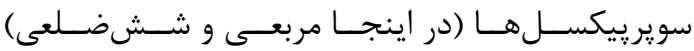

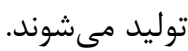

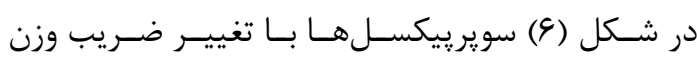

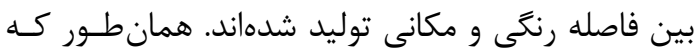
مشـخص اسـت وزن برابــر بــين اطلاعــات رنغــى و اطلاعات مكـانى منجـر بـهـ حساسـيت بـالاى الحَـوريته به نويزها و تغييرات كوجى درجه خاكسترى مسىشـود. با افزايش ضـريب وزن و دخالـت بيشـتر معيـار فاصـله،

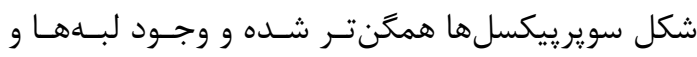
كوشههاى تيز در مرز سوير بيكسل ها كـاهش مسى يابـد.

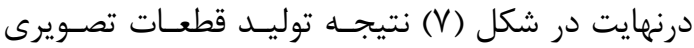

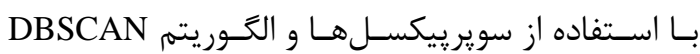

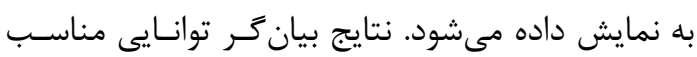

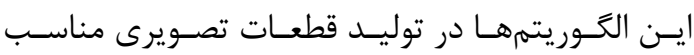

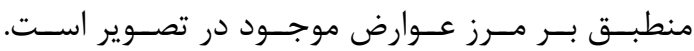

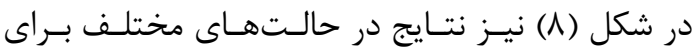

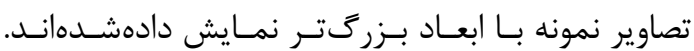

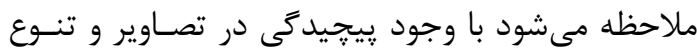

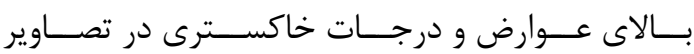

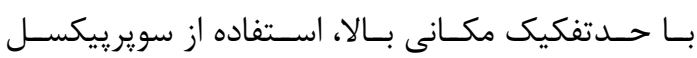

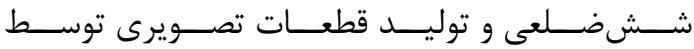

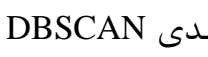

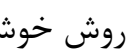
منجر به نتايج قابل قبولى ميىشود.

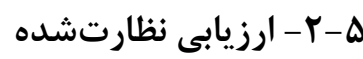

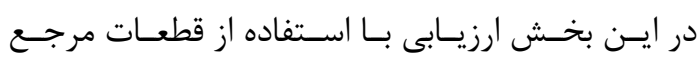

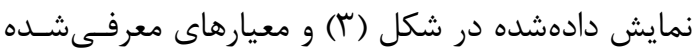

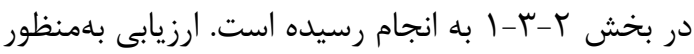

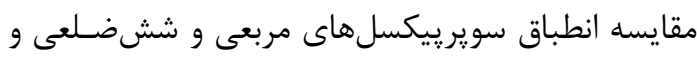

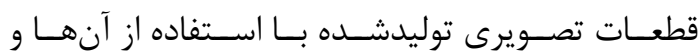
الكوريتم DBSCAN با قطعات تصويرى مرجع به انجـام تصام

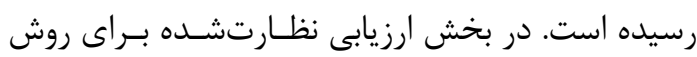

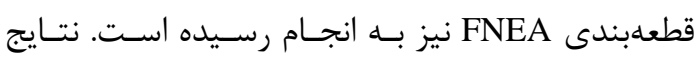

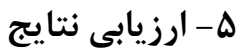

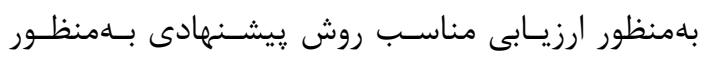

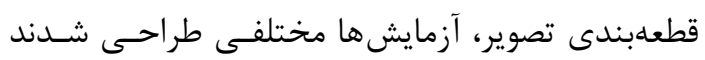

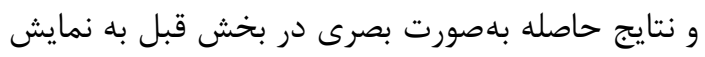
درآمدند. بهمنظور انجام بررسى كامل، شش ناحية داصيه از دو دو

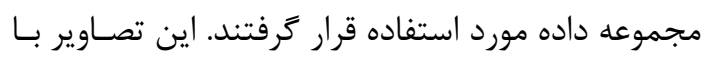

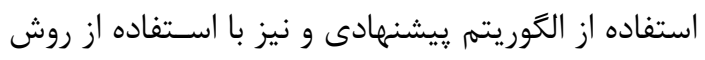

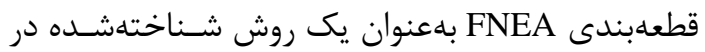

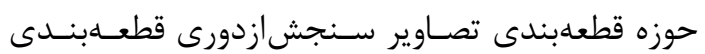

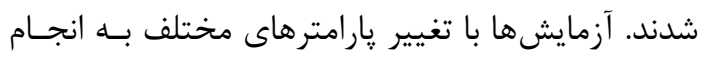

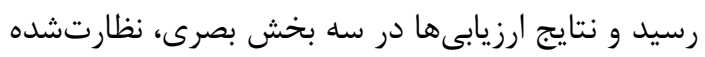
و نظارتنشده در ادامه تشريح مىشود.

$$
\text { ه-1- ارزيابى بصرى }
$$

در ارزيابى بصـرى همـان طـور كـه عنـوان شـد، كـاربر

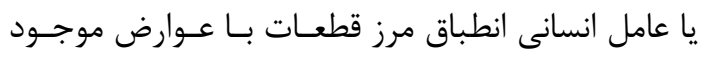

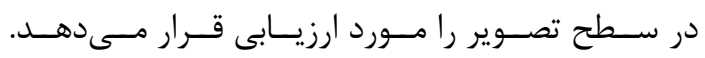

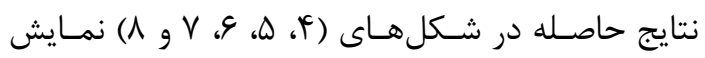

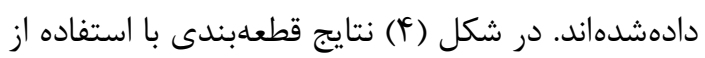
الكوريتم FNEA به تصوير كشيده شده است. همانطوان إنور

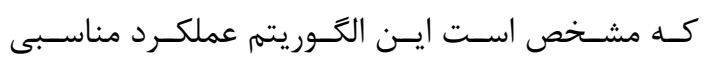

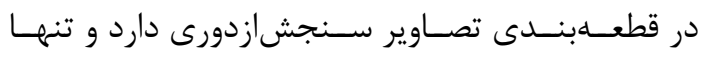

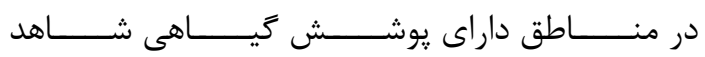

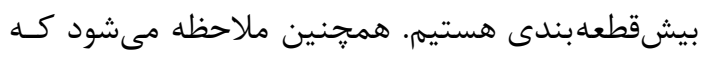

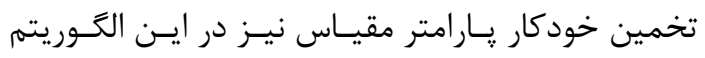

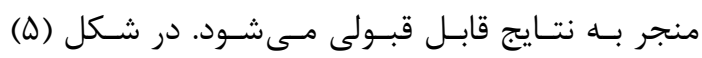

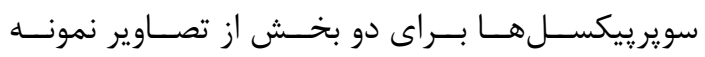

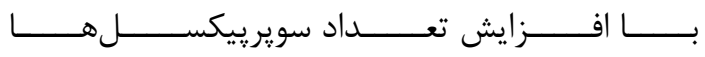

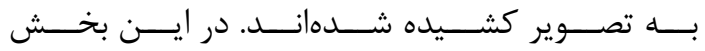

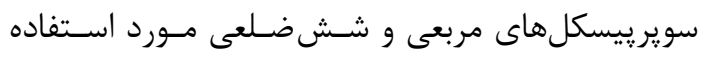

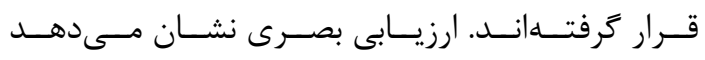

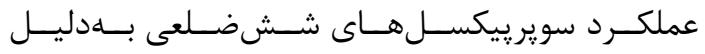

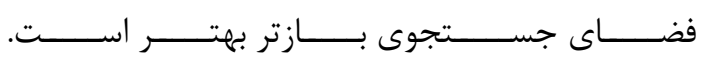

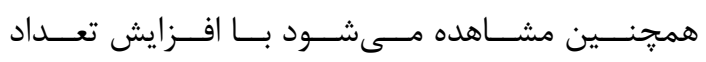

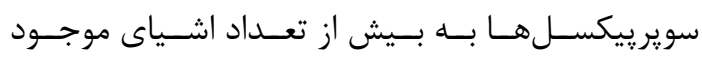


هر سه باند موجود در هر تصوير براى قطعات تصـويرى

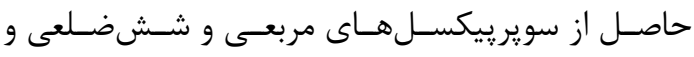
الكوريتم DBSCAN و نيز قطعـات تصـويرى حاصـل از

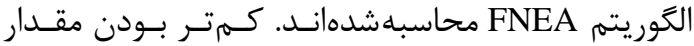
واريـانس وزندار بــه معنـى توليـــ قطعـات تصــويرى

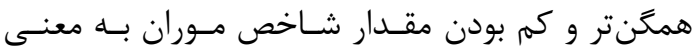
تمايز مناسب بين قطعـات تصـويرى مجـاور مـىباشـد. نتايج حاصله در شكل ( • () نمايش دادهشداند. همــانطــور كــهـه در شــكل ( • ) مشــخص اســت

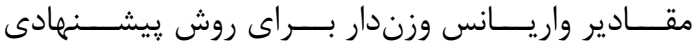

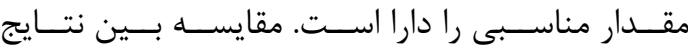

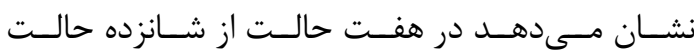

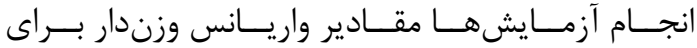
روش ييشنهادى كممتر از الخـوريتم FNEA بــوده اسـت.

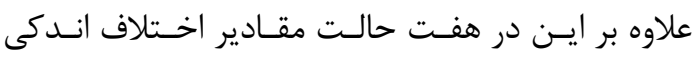

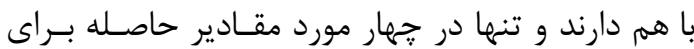
الكوريتم FNEA در سطح يـايينتـرى قـرار كرفتـهانـد.

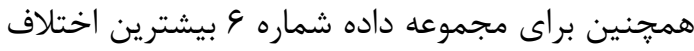

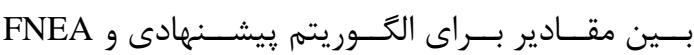

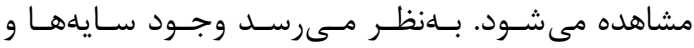
بيِجيدگى تصوير باعث رخداد اين اتفاق باشد. مقايسه نتايج حاصله براى سويرييسـكلهـاى مربعى و ششضلعى نشان مى دهد در ده حالت از هجـده حالـت

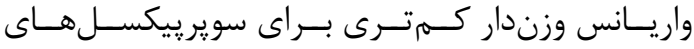

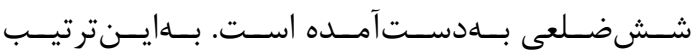
مشخص مى شود انعطاف بيشـتر محسدوده جسـتوجــو مىتواند منجر به نتايج بهتر در انجام قطعهبندى شود.

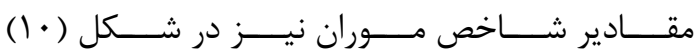

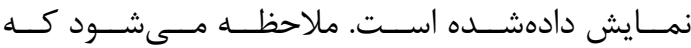

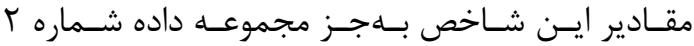
براى ساير حالتها در سطح تقريبا يكسانى قرار دارند و

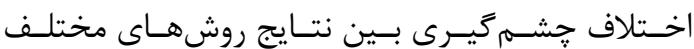
مورد آزمايش مشاهده نمىشود.

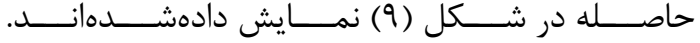

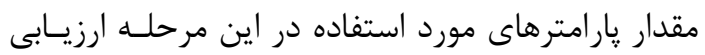
مقادير يارامترهاى مـورد اسـتفاده بايـد تـا حــد ممكـن

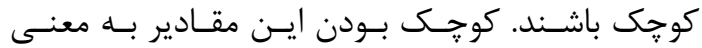
انطباق مناسب بين سويرييكسلها و يا قطعات تصويرى

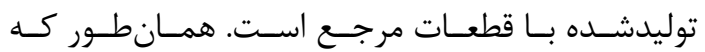
مشخص است مقادير محاسبهشده براى سويرييكسلهـا

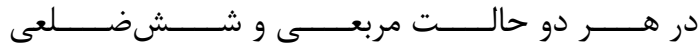

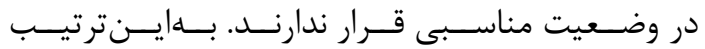

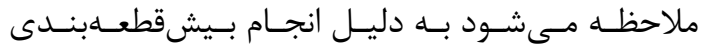
توسط سوير بيكسل ها اين اتفاق رخ داده است.

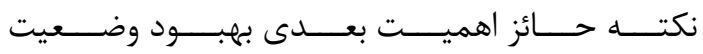

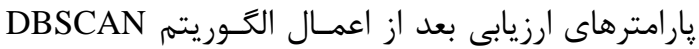

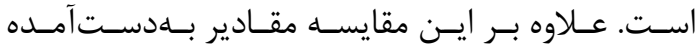

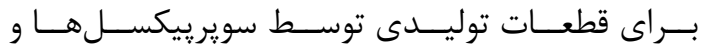

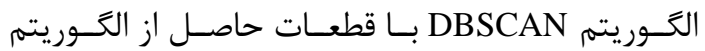

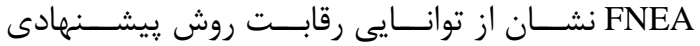
با الخوريتم شناخته شده FNEA را دارد. معيار كم ادغام

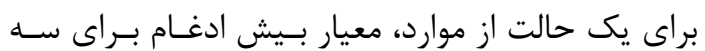

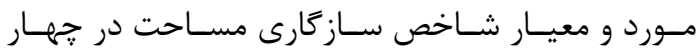

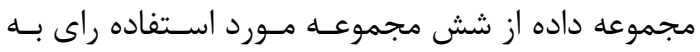

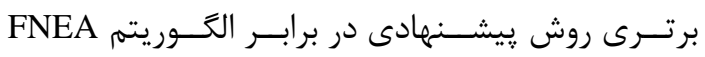

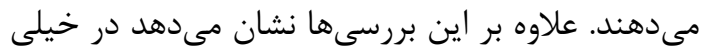
از موارد نيز اختلاف جشمَّيرى بين اين مقـادير وجـود

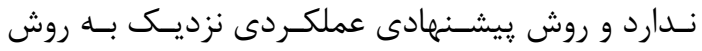

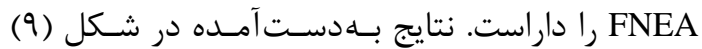
نشان مىدهد كه استفاده از روشهاى خودكار بهمنظور

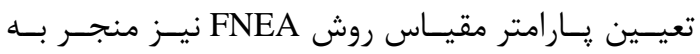
بهبود قابل ملاحظه نتايج ايـن روش نمسى شـود و حتى ريى در بيشـتر مـوارد انتخـاب ايـن يــارامتر توسـط ايراتـور منجر به حصول نتايج بهترى شده است. ه-r- ارزيابى نظارتنشده در اين بخش مقادير واريانس وزندار و شـاخص مـوران بهمنظور ارزيابى اسـتفاده شـدهانـد. ايـن مقـادير بـراى 

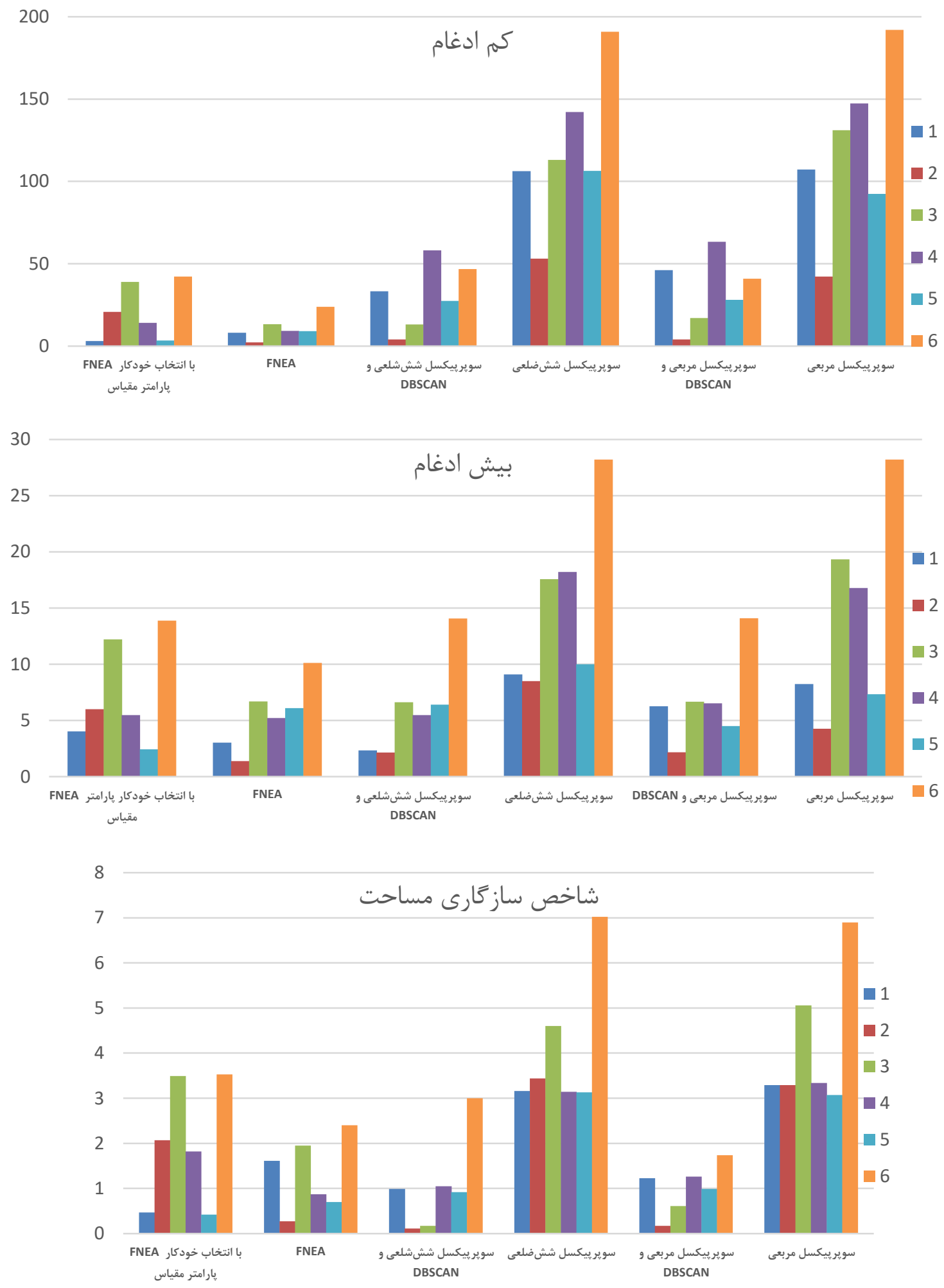

شكل 9 : نمودارهاى مقادير كمادغام، بيشادغام و شاخص سازكارى مساحت براى مجموعه دادههاى مورد استفاده. 


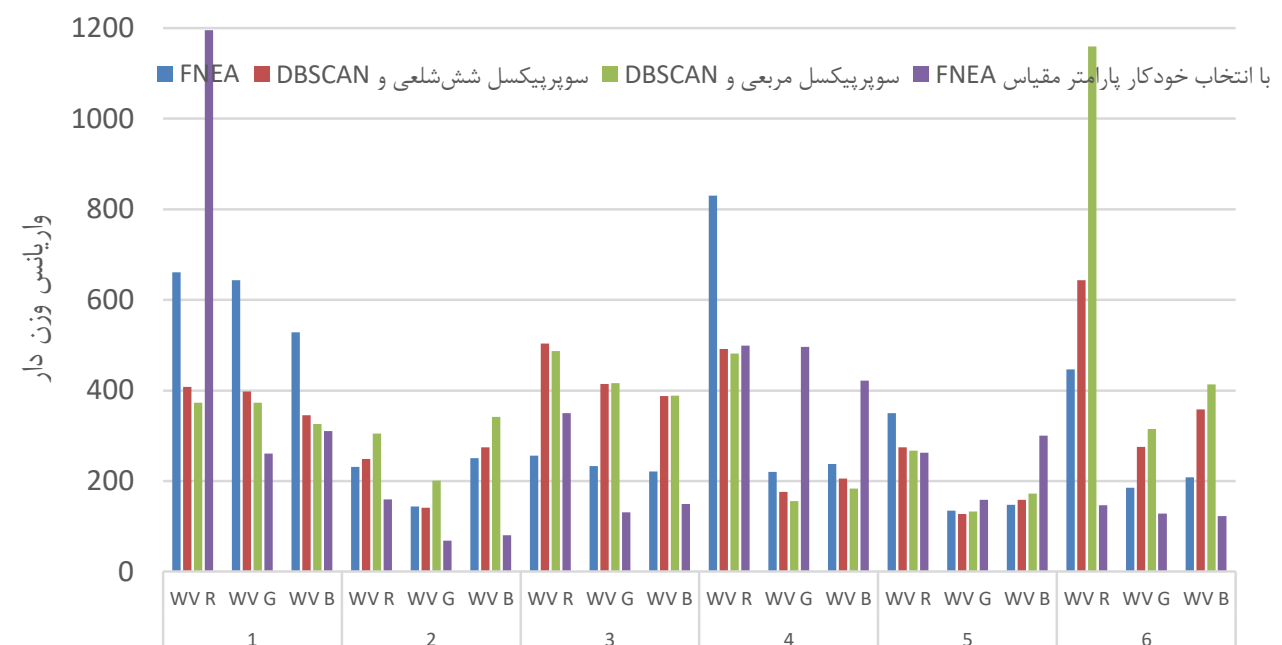

شاخص موران

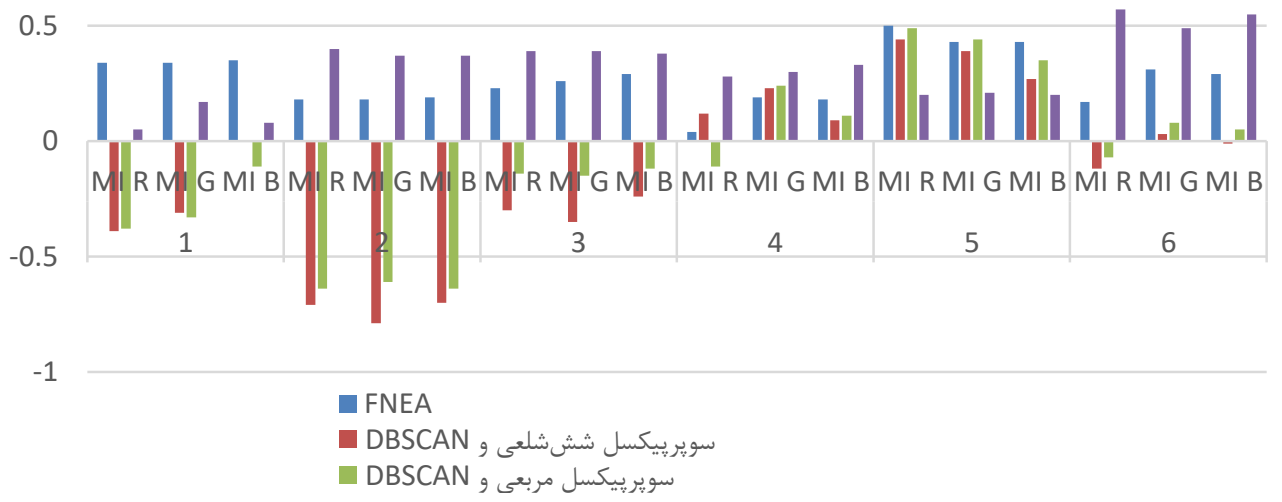

شكل • ا : نمودارهاى مقادير واريانس وزندار و شاخص موران براى مجموعه دادههاى مورد استفاده.

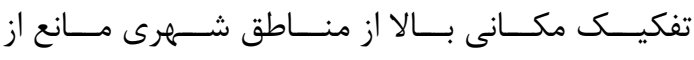

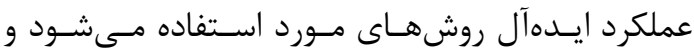
ملاحظه مىشود كه تخمين خودكار :ارامتر مقياس نيـز

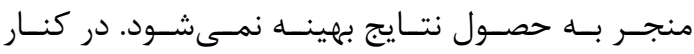

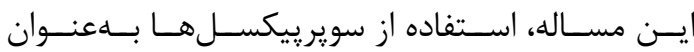
يك مرحله ميانى و توليد قطعات تصويرى با اسـتفاده از

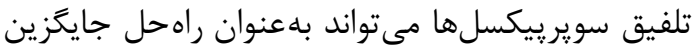

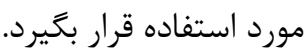

در نهايت نتايج ارزيابى نظارتشده و نظارتنشـده بـراى

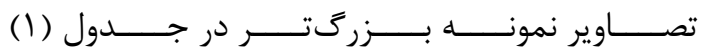

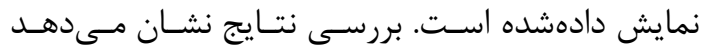

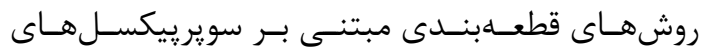

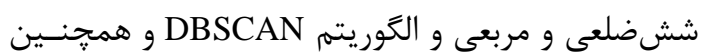

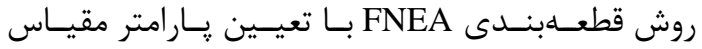
توسط كاربر نتايج بهترى را در مقايسه با سـاير روشهـا بـاسيا

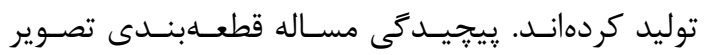

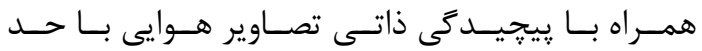


ارزيابى توانايى الكوريتم سويرييكسل SLIC به همراه....

احمد هداوند و ديخر همكاران

جدول ا : نتايج ارزيابى نظارتشده و نظارتنشده براى دو مجموعه داده با ابعاد بزرى

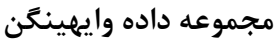

\begin{tabular}{|c|c|c|c|c|c|c|c|c|c|}
\hline WV R & WV G & WV B & MI R & MI G & MI B & Umerging & Omerging & AFI & \\
\hline TVVG/TG & \&YV/Td & $\Delta V \cdot / T$ & س &.$/ 1 \mathrm{~V}$ & .119 & $9 / 90$ & $r T / \cdot V$ & $1 / 01$ & 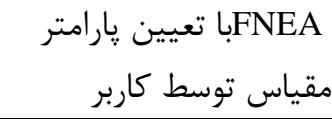 \\
\hline$q \uparrow \Delta / \wedge \Lambda$ & rqq/4q & TrN/VG & .ハ & $\cdot / 41$ & $\cdot / T$ & $f \varphi / D \mid$ & rA/VV & G/VG & 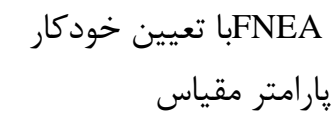 \\
\hline G|r/g| & rqK/Td & $r r V / F F$ & $\cdot / \Delta \Lambda$ & . /VG & $\cdot / V$ & IT $\Delta G / G V$ & W & $19 / 91$ & سوير ييكسل ششضلى \\
\hline $1 \cdot F F / T$ & $r q \cdot / q \psi$ & r & $-\cdot / \cdot r$ & $\cdot / T$ &.$/ 10$ & سז/FI & F & $N / \Delta \varphi$ & الكوريرييكسل ششم DBSCAN \\
\hline$\Delta V \cdot / I$ & r rq/яq & | & .194 & $\cdot / \mathrm{VA}$ & . & |qтq/.r & IFV/GT & $|/| q \mid$ & سوير يِكسل مربعى \\
\hline $1.99 / \Delta r$ & $F r \cdot / \Delta F$ & $F \cdot \varepsilon / \Delta r$ & $-\cdot / \cdot 1$ & $\cdot / r$ & מו & $\mid F \Delta / 1 \wedge$ & $F I / T \Delta$ & ᄉ/AV & سويري الخوريتم \\
\hline
\end{tabular}

مجموعه داده يهبباد

\begin{tabular}{|c|c|c|c|c|c|c|c|c|c|}
\hline WV R & WV G & WV B & MI R & MI G & MI B & Umerging & Omerging & AFI & \\
\hline$r \wedge 1 / \cdot r$ & Fा/199 & $F Y \Delta / \Delta T$ & $\cdot / \pi q$ & $\cdot / T V$ &.$/ 4 G$ & $r F / 1$ & Tr/TV & $\Delta / \wedge \Lambda$ & 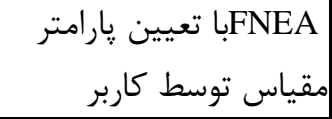 \\
\hline frq/.r & rVI/ru & $r \cdot 9 / 9 r$ & $\cdot / \uparrow \wedge$ & . & $\cdot / F V$ & $\Delta r / F l$ & rV/9V & V/Ar & 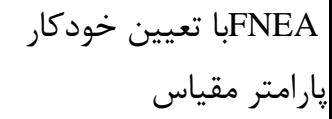 \\
\hline גזוצr & $r \cdot \Delta / 19$ & שת/rس & $\cdot / \mathrm{V}$ & .191 & . IVG & $111 \mathrm{~V} / 90$ & $11 \mathrm{~V} / 99$ & $19 / 4 \pi$ & سوير يِكسل ششضلى \\
\hline NזG/Fd & $\Lambda \Delta Y / V q$ & VIr/GD & $\cdot \pi \wedge$ & $\cdot / T 1$ & $\cdot r \Lambda$ & I I I & $V \cdot / \mathbb{A}$ & f/99 & سويريّكسل ششضعى و \\
\hline וd/טאז & qس & אגוq & $\cdot / V V$ & $.19 \mathrm{~V}$ &.$/ V F$ & I & $1 \wedge \varepsilon / T$ & $19 / 14$ & سوير:يكسل مربعى \\
\hline$q \cdot q / \Delta \Lambda$ & $q r G / r$ & $V V \cdot / T$ & $\cdot|f|$ & $\cdot / T F$ & •rV & IDH/VG & G)/VA & $F / M I$ & الكوريريتمسل مربعى و \\
\hline
\end{tabular}

مكـانى ه/ T و 9 سـانتى متــر شـامل عـوارض شـهرى و 9- و نتيجه كياهى مورد ارزيابى قرار كرفت. ارزيابىها به ســه شـيوه بصرى، نظارتشده و نظارتنشده به انجام رسيد.

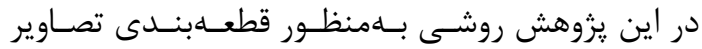

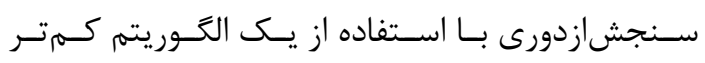

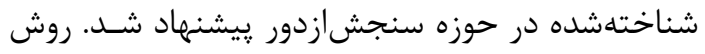

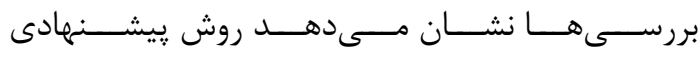
ييشنهادى مبتنى بر توليد سويرييكسل ها با اسـتفاده از

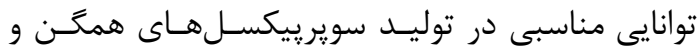

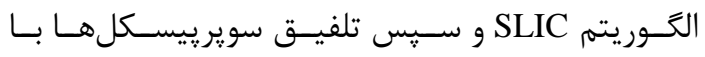

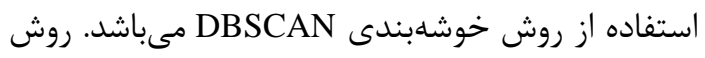

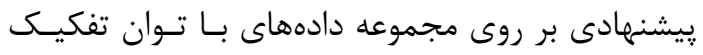




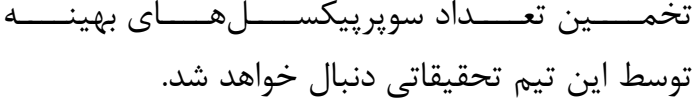

[1] G. G. Wilkinson, "Results and implications of a study of fifteen years of satellite image classification experiments," Geoscience and Remote Sensing, IEEE Transactions on, vol. 43, pp. 433-440, 2005.

[2] A. Hadavand, M. Saadatseresht, and S. Homayouni, "A NEW FRAMEWORK FOR OBJECT-BASED IMAGE ANALYSIS BASED ON SEGMENTATION SCALE SPACE AND RANDOM FOREST CLASSIFIER," The International Archives of Photogrammetry, Remote Sensing and Spatial Information Sciences, vol. 40, p. 263, 2015.

[3] G. Schumann, R. Hostache, C. Puech, L. Hoffmann, P. Matgen, F. Pappenberger, et al., "High-resolution 3-D flood information from radar imagery for flood hazard management," Geoscience and Remote Sensing, IEEE Transactions on, vol. 45, pp. 1715-1725, 2007.

[4] Y. Du, P. M. Teillet, and J. Cihlar, "Radiometric normalization of multitemporal high-resolution satellite images with quality control for land cover change detection," Remote sensing of Environment, vol. 82, pp. 123-134, 2002.

[5] C. Zhang and J. M. Kovacs, "The application of small unmanned aerial systems for precision agriculture: a review," Precision agriculture, vol. 13, pp. 693-712, 2012.

[6] N. R. Pal and S. K. Pal, "A review on image segmentation techniques," Pattern recognition, vol. 26, pp. 1277-1294, 1993.

[7] O. Veksler, Y. Boykov, and P. Mehrani, "Superpixels and supervoxels in an energy optimization framework," in Computer

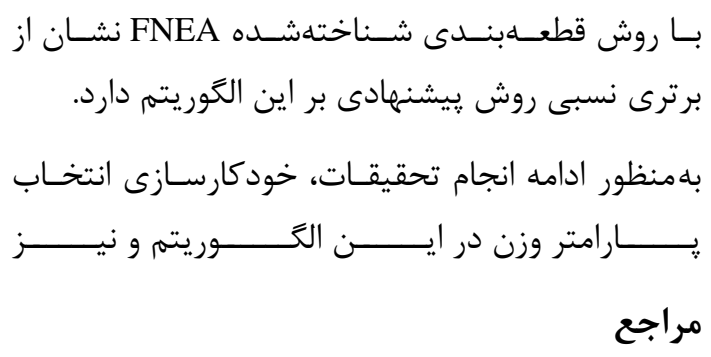

Vision-ECCV 2010, ed: Springer, 2010, pp. 211-224.

[8] V. Dey, Y. Zhang, and M. Zhong, A review on image segmentation techniques with remote sensing perspective: na, 2010.

[9] S. Sahli, P.-L. Duval, Y. Sheng, and D. A. Lavigne, "Robust vehicle detection in aerial images based on salient region selection and superpixel classification," in SPIE Defense, Security, and Sensing, 2011, pp. 80200L80200L-11.

[10] G. Zhang, X. Jia, and N. M. Kwok, "Super pixel based remote sensing image classification with histogram descriptors on spectral and spatial data," in Geoscience and Remote Sensing Symposium (IGARSS), 2012 IEEE International, 2012, pp. 43354338.

[11]L. Fang, S. Li, X. Kang, and J. A. Benediktsson, "Spectral-Spatial Classification of Hyperspectral Images With a Superpixel-Based Discriminative Sparse Model," Geoscience and Remote Sensing, IEEE Transactions on, vol. 53, pp. 41864201, 2015.

[12]G. Zhang, X. Jia, and J. Hu, "SuperpixelBased Graphical Model for Remote Sensing Image Mapping," Geoscience and Remote Sensing, IEEE Transactions on, vol. 53, pp. 5861-5871, 2015.

[13] J. Shi and J. Malik, "Normalized cuts and image segmentation," Pattern Analysis and Machine Intelligence, IEEE Transactions on, vol. 22, pp. 888-905, 2000.

[14]D. Comaniciu and P. Meer, "Mean shift: A robust approach toward feature space analysis," Pattern Analysis and Machine Intelligence, IEEE Transactions on, vol. 24, 
pp. 603-619, 2002.

[15]L. Vincent and P. Soille, "Watersheds in digital spaces: an efficient algorithm based on immersion simulations," IEEE Transactions on Pattern Analysis \& Machine Intelligence, pp. 583-598, 1991.

[16] A. Levinshtein, A. Stere, K. N. Kutulakos, D. J. Fleet, S. J. Dickinson, and K. Siddiqi, "Turbopixels: Fast superpixels using geometric flows," Pattern Analysis and Machine Intelligence, IEEE Transactions on, vol. 31, pp. 2290-2297, 2009.

[17] R. Achanta, A. Shaji, K. Smith, A. Lucchi, P. Fua, and S. Süsstrunk, "Slic superpixels," 2010.

[18] J. MacQueen, "Some methods for classification and analysis of multivariate observations," in Proceedings of the fifth Berkeley symposium on mathematical statistics and probability, 1967, pp. 281-297.

[19]C. Connolly and T. Fleiss, "A study of efficiency and accuracy in the transformation from RGB to CIELAB color space," IEEE Transactions on Image Processing, vol. 6, pp. 1046-1048, 1997.

[20] R. Achanta, A. Shaji, K. Smith, A. Lucchi, P. Fua, and S. Susstrunk, "SLIC superpixels compared to state-of-the-art superpixel methods," Pattern Analysis and Machine Intelligence, IEEE Transactions on, vol. 34, pp. 2274-2282, 2012.

[21] M. Ester, H.-P. Kriegel, J. Sander, and X. $\mathrm{Xu}$, "A density-based algorithm for discovering clusters in large spatial databases with noise," in Kdd, 1996, pp. 226-231.

[22] B. Johnson and Z. Xie, "Unsupervised image segmentation evaluation and refinement using a multi-scale approach," ISPRS Journal of Photogrammetry and Remote Sensing, vol. 66, pp. 473-483, 2011.

[23]H. Zhang, J. E. Fritts, and S. A. Goldman, "Image segmentation evaluation: A survey of unsupervised methods," Computer Vision and Image Understanding, vol. 110, pp. 260280, 2008 .
[24] Y. J. Zhang, "Evaluation and comparison of different segmentation algorithms," Pattern recognition letters, vol. 18, pp. 963-974, 1997.

[25] R. M. Haralick and L. G. Shapiro, "Image segmentation techniques," Computer vision, graphics, and image processing, vol. 29, pp. 100-132, 1985.

[26] L. Yang, F. Albregtsen, T. Lønnestad, and P. Grøttum, "A supervised approach to the evaluation of image segmentation methods," in Computer Analysis of Images and Patterns, 1995, pp. 759-765.

[27]A. Lucieer and A. Stein, "Existential uncertainty of spatial objects segmented from satellite sensor imagery," IEEE Transactions on Geoscience and Remote Sensing, vol. 40, pp. 2518-2521, 2002.

[28] G. Espindola, G. Câmara, I. Reis, L. Bins, and A. Monteiro, "Parameter selection for region - growing image segmentation algorithms using spatial autocorrelation," International Journal of Remote Sensing, vol. 27, pp. 3035-3040, 2006.

[29] T. Blaschke, G. J. Hay, M. Kelly, S. Lang, P. Hofmann, E. Addink, et al., "Geographic Object-Based Image Analysis-Towards a new paradigm," ISPRS Journal of Photogrammetry and Remote Sensing, vol. 87, pp. 180-191, 2014.

[30] o. r. w. senseFly. (2015). Available: https://www.sensefly.com/drones/exampledatasets.html

[31]U. C. Benz, P. Hofmann, G. Willhauck, I. Lingenfelder, and M. Heynen, "Multiresolution, object-oriented fuzzy analysis of remote sensing data for GIS-ready information," ISPRS Journal of Photogrammetry and Remote Sensing, vol. 58, pp. 239-258, 2004.

[32] J. Im, L. J. Quackenbush, M. Li, and F. Fang, "Optimum Scale in Object - Based Image Analysis," Scale Issues in Remote Sensing, pp. 197-214, 2014.

[33]L. Drăguţ, D. Tiede, and S. R. Levick, "ESP: 
a tool to estimate scale parameter for multiresolution image segmentation of remotely sensed data," International Journal of Geographical Information Science, vol. 24, pp. 859-871, 2010. 


\title{
Evaluation of SLIC superpixel and DBSCAN clustering algorithms in segmentation of ultra-high resolution remote sensing imagery over urban areas
}

\author{
Ahmad Hadavand ${ }^{* 1}$, Mohamad Saadatseresht ${ }^{2}$, Saeed Homayouni ${ }^{3}$, Zeinab Gharib Bafghi ${ }^{4}$
}

1- PhD student of Photogrammetry in School of Surveying and Geospatial Engineering, College of Engineering, University of Tehran.

2- Associate professor in School of Surveying and Geospatial Engineering, College of Engineering, University of Tehran

3- Assistant professor in Department of Geography, University of Ottawa, Canada

4- PhD student of Photogrammetry, German Aerospace Center (DLR)

\begin{abstract}
By increasing the spatial resolution of remote sensing imaging sensors, the image analyzing paradigm is moving towards the object based image analysis approaches, instead of single pixels. Among the common segmentation algorithms, super-pixel methods are presenting themselves as the new tools in computer vision. In this paper, the capabilities of a state-of-the-art super-pixel algorithm, namely called SLIC, is investigated for creating image segments from ultra-high resolution remote sensing images. In our proposed method, square and hexagonal super-pixels were formed and then DBSCAN clustering algorithm is employed to build image segments from these pixels. The results were compared to image segments obtained from FNEA algorithm, a well-known method for remote sensing image segmentation. Visual and quantitative evaluations demonstrate the efficiency of proposed method.
\end{abstract}

Key words:. Super-pixel, Segmentation, Ultra-high resolution Images, Remote Sensing.

Correspondence Address: Photogrammetry Group, School of Surveying and Geospatial Engineering, College of Engineering, University of Tehran, University of Tehran, Tehran

Tel: +989128631959.

Email : ahadavand@ut.ac.ir 